\title{
RESEARCH
}

Open Access

\section{Human chorionic villous mesenchymal stem/stromal cells protect endothelial cells from injury induced by high level of glucose}

Y. S. Basmaeil ${ }^{1}$, A. M. Al Subayyil ${ }^{1}$, T. Khatlani', E. Bahattab², M. Al-Alwan³ , F. M. Abomaray ${ }^{4,5}$, B. Kalionis ${ }^{6}$, M. A. Alshabibi ${ }^{1}$, A. S. AlAskar ${ }^{1,7,8}$ and M. H. Abumaree ${ }^{1,9^{*}}$ (D)

\begin{abstract}
Background: Mesenchymal stem/stromal cells derived from chorionic villi of human term placentae (pMSCs) protect human endothelial cells from injury induced by hydrogen peroxide $\left(\mathrm{H}_{2} \mathrm{O}_{2}\right)$. In diabetes, elevated levels of glucose (hyperglycaemia) induce $\mathrm{H}_{2} \mathrm{O}_{2}$ production, which causes the endothelial dysfunction that underlies the enhanced immune responses and adverse complications associated with diabetes, which leads to thrombosis and atherosclerosis. In this study, we examined the ability of pMSCs to protect endothelial cell functions from the negative impact of high level of glucose.

Methods: pMSCs isolated from the chorionic villi of human term placentae were cultured with endothelial cells isolated from human umbilical cord veins in the presence of glucose. Endothelial cell functions were then determined. The effect of pMSCs on gene expression in glucose-treated endothelial cells was also determined.

Results: PMSCs reversed the effect of glucose on key endothelial cell functions including proliferation, migration, angiogenesis, and permeability. In addition, pMSCs altered the expression of many genes that mediate important endothelial cell functions including survival, apoptosis, adhesion, permeability, and angiogenesis.

Conclusions: This is the first comprehensive study to provide evidence that pMSCs protect endothelial cells from glucose-induced damage. Therefore, pMSCs have potential therapeutic value as a stem cell-based therapy to repair glucose-induced vascular injury and prevent the adverse complications associated with diabetes and cardiovascular disease. However, further studies are necessary to reveal more detailed aspects of the mechanism of action of pMSCs on glucose-induced endothelial damage in vitro and in vivo.
\end{abstract}

Keywords: Placenta, Chorionic villous mesenchymal stromal cells, Endothelial cells, Glucose, Proliferation, Migration, Monocyte invasion, Endothelium permeability, Gene expression

\footnotetext{
* Correspondence:

mohamedabumaree@hotmail.com; abumareem@ksau-hs.edu.sa

${ }^{1}$ Stem Cells and Regenerative Medicine Department, King Abdullah International Medical Research Centre, King Abdulaziz Medical City, Ministry of National Guard Health Affairs, P.O. Box 22490, Mail Code 1515, Riyadh 11426, Saudi Arabia

${ }^{9}$ College of Science and Health Professions, King Saud Bin Abdulaziz University for Health Sciences, King Abdulaziz Medical City, Ministry of National Guard Health Affairs, P.O. Box 3660, Mail Code 3124, Riyadh 11481, Saudi Arabia

Full list of author information is available at the end of the article
}

(c) The Author(s). 2018 Open Access This article is distributed under the terms of the Creative Commons Attribution 4.0 International License (http://creativecommons.org/licenses/by/4.0/), which permits unrestricted use, distribution, and reproduction in any medium, provided you give appropriate credit to the original author(s) and the source, provide a link to the Creative Commons license, and indicate if changes were made. The Creative Commons Public Domain Dedication waiver (http://creativecommons.org/publicdomain/zero/1.0/) applies to the data made available in this article, unless otherwise stated. 


\section{Background}

Diabetes is a metabolic disorder characterized by hyperglycaemia, insulin resistance, and relative insulin deficiency [1]. Diabetes is associated with vascular complications that contribute to morbidity and mortality in diabetic patients [2-4]. In diabetic patients, hyperglycaemia stimulates the production of reactive oxygen species in the endothelium, which play an essential role in the development of vascular damage and contribute to the incidence of thrombotic events [5-8]. Indeed, diabetes shares similar features with cardiovascular diseases, which also features enhanced responses of inflammatory cells and increased formation of thrombosis because of endothelial cell dysfunction [9, 10].

Injured endothelial cells express elevated levels of adhesion molecules and have enhanced permeability [9, 10]. These two events stimulate the recruitment of immune cells, such as monocytes, as well as the entry of low-density lipoprotein cholesterol (LDL) from the blood vessel lumen into the wall [5-8]. Subsequently, LDL is oxidized to ox-LDL and is taken up by macrophages, which leads to the formation of foam cells, increases inflammatory responses, and leads to the deposition of collagen [5-8]. These events lead to the formation of atherosclerotic plaques, and the subsequent rupture of these plaques activates platelets and culminates in thrombosis [5-8]. Therefore, improving or alleviating the effects of endothelial cell damage in diabetes is a potential therapeutic target, with the expected outcome of repairing vascular dysfunction and preventing complications associated with diabetes, such as thrombosis and atherosclerosis.

Mesenchymal stem cells (MSCs) are multipotent stromal cells that are isolated from adult and fetal tissues, such as placenta [11]. Previously, we isolated MSCs from the chorionic villi of human term placentae (pMSCs) and reported their unique ability to regulate many of the critical cellular functions of their target cells [11]. Moreover, pMSCs show immunosuppressive properties that make allogeneic transplantation possible [12, 13]. Recently, we reported that pMSCs protect endothelial cells from damage induced by an oxidative stress mediator (i.e. hydrogen peroxide) [14]. Therefore, pMSCs have the key functional properties that make them a promising therapeutic tool for treating inflammatory diseases.

Here, we initially examined the ability of pMSCs to protect various important endothelial cell functions from oxidative stress induced by another oxidative stress mediator; glucose. To better understand the mechanism of endothelium damage repair following exposure to glucose and pMSC treatment, we investigated gene expression changes in a panel of endothelial genes that mediate important cellular functions. We report that pMSCs protect particular endothelial cell functions (i.e. proliferation, migration, permeability, and tube network formation (angiogenesis)) from glucose. In addition, pMSCs modify the effect of glucose on the expression of many genes that mediate endothelial cell functions. These data suggest that pMSCs have a protective function on endothelial cells in an oxidative stress environment induced by glucose. Thus, pMSCs are promising candidates for a stem cell-based therapy to repair endothelial cell injury induced by high glucose, and prevent complications associated with this injury. However, further studies are required to reveal more detailed aspects of the mechanism of action of pMSCs on glucose-induced endothelial damage both in vitro and in vivo.

\section{Methods}

Ethics of experimentation and collection of human placentae and umbilical cords

The study was approved by the institutional research board (Reference \# IRBC/246/13) at King Abdulla International Medical Research Centre (KAIMRC), Saudi Arabia. Samples (i.e. placentae and umbilical cords) were obtained from uncomplicated human pregnancies (3840 gestational weeks) following informed patient consent, and then processed immediately. All clinical and experimental procedures were performed in compliance with KAIMRC research guidelines and regulations.

\section{Isolation and culture of pMSCs}

MSCs from the chorionic villi of human term placenta (pMSCs) were isolated using our published method [11]. Briefly, small pieces ( $\sim 40 \mathrm{mg}$ total wet weight) of the chorionic villi were washed thoroughly with sterile phosphate buffered saline (PBS, pH 7.4) and then incubated in a solution of DMEM-F12 (Life Technologies, Grand Island, NY, USA) containing 2.5\% trypsin (Life Technologies), 270 unit/ml DNase (Life Technologies), and antibiotics $(100 \mathrm{U} / \mathrm{l}$ penicillin and $100 \mu \mathrm{g} / \mathrm{ml}$ streptomycin). After gentle rotation overnight at $4{ }^{\circ} \mathrm{C}$, tissues were washed thoroughly with PBS and the tissues were then cultured in a complete DMEM-F12 culture medium containing 10\% MSC Certified fetal bovine serum (MSC-FBS; Life Technologies), $100 \mu \mathrm{g} / \mathrm{ml}$ of L-glutamate, and antibiotics $(100 \mathrm{U} / \mathrm{l}$ penicillin and $100 \mu \mathrm{g} / \mathrm{ml}$ streptomycin). Tissues were then incubated at $37{ }^{\circ} \mathrm{C}$ in a humidified atmosphere containing $5 \% \mathrm{CO}_{2}$, within a cell culture incubator. When cells migrated out of the explants, they were harvested with TrypLE ${ }^{\mathrm{rm}}$ Express detachment solution (Life Technologies) and then characterized by flow cytometry using well-characterized MSCs and haematopoietic markers (Table 1). The MSC differentiation potential into adipocytes, chondrocytes, and osteocytes was evaluated as published previously 
Table 1 Antibodies used in this study

\begin{tabular}{ll}
\hline MSC positive marker & Haematopoietic marker \\
\hline CD44 & CD14 \\
CD90 & CD19 \\
CD105 & CD40 \\
CD146 & CD45 \\
CD166 & CD80 \\
HLA-ABC & CD83 \\
& CD86 \\
& HLA-DR \\
\hline
\end{tabular}

MSC mesenchymal stem cell

[11]. pMSCs (passage 2) from a total of 20 placentae were used in this study.

Isolation and culture of human umbilical vein endothelial cells

Endothelial cells from human umbilical cord veins (HUVECs) were isolated according to our published method [15]. Briefly, the cannulated umbilical vein was rinsed with sterile PBS ( $\mathrm{pH} 7.4)$ several times, and then filled with a PBS solution containing $6 \mathrm{mg} / \mathrm{ml}$ collagenase type II (Catalog \# 17101-015; Life Technologies). After 25 min of incubation at $37{ }^{\circ} \mathrm{C}$ in a cell culture incubator, HUVECs were collected, resuspended in a complete endothelial cell growth medium (Catalog \# PCS-100-041 ${ }^{\mathrm{Tm}}$; ATCC, USA), and then cultured at $37{ }^{\circ} \mathrm{C}$ in a cell culture incubator. Before using HUVECs in subsequent experiments, they were characterized by flow cytometry using a CD31 endothelial cell marker (R \& D Systems, Abingdon, UK). HUVECs (> 95\% purity) from passages $3-5$ of a total of 30 umbilical cords were used in this study.

\section{Cell proliferation in response to glucose}

Cells (pMSCs and HUVECs) at a density of $5 \times 10^{3}$ were seeded in wells of 96-well culture plates containing a complete cell culture growth medium (i.e. complete DMEMF-12 culture medium for pMSCs, and complete endothelial cell growth medium for HUVECs) and then incubated at $37{ }^{\circ} \mathrm{C}$ in a cell culture incubator. At $75 \%$ confluency, non-adherent pMSCs or HUVECs were removed and cells were cultured in a complete cell culture growth medium with or without glucose (Prince Care Pharma Pvt. Ltd, India), and then incubated at $37{ }^{\circ} \mathrm{C}$ in a cell culture incubator. Different concentrations of glucose (0-2000 mM) and various culture time points (i.e. 24,48 , and $72 \mathrm{~h}$ ) were examined. The viability of pMSCs and HUVECs was determined by the Trypan blue exclusion assay.

The proliferation of pMSCs and HUVECs was evaluated after each indicated culture time point (i.e. 24, 48, and $72 \mathrm{~h})$ by a tetrazolium compound (3-(4,5-dimethylthiazol-
2-yl)-5-(3-carboxymethoxyphenyl)-2-(4-sulfophenyl)-2H-tetrazolium, inner salt (MTS)) kit (Catalog \# G5421, CellTiter 96 Aqueous Non-Radioactive Cell Proliferation Assay; Promega, Germany), as described previously [14]. The blank was cells incubated in MTS solution in a complete cell culture growth medium. Results were presented as means ( \pm standard errors). Each experiment was performed in triplicate and repeated with five independent pMSC (passage 2) and HUVEC (passage 3-5) preparations.

HUVEC proliferation in response to glucose in presence of different treatments of pMSCs

HUVECs $\left(5 \times 10^{3}\right.$ cells $)$ were seeded in wells of 96-well culture plate containing a complete endothelial cell growth medium and cultured at $37{ }^{\circ} \mathrm{C}$ in a cell culture incubator. After $24 \mathrm{~h}$, adherent HUVECs were cultured alone, or co-cultured with different concentrations (20, 50 , and $100 \mathrm{mM}$ ) of glucose in the presence of $25 \%$ CMpMSC (conditioned medium of unstimulated pMSCs, produced as described previously [14]) and pMSCs (whole cells) at a ratio of 1 HUVEC:1 pMSC. These concentrations and ratios of CMpMSC and pMSCs, respectively, were chosen because they can induce optimum HUVEC proliferative responses as reported previously by us [14]. Cells were then cultured in a complete endothelial cell growth medium for $72 \mathrm{~h}$ at $37^{\circ} \mathrm{C}$ in a cell culture incubator.

HUVEC proliferation was then evaluated by the MTS assay as described previously [14]. Before adding pMSCs to the HUVEC culture, pMSCs were treated with $25 \mu \mathrm{g}$ / $\mathrm{ml}$ Mitomycin $\mathrm{C}$ to inhibit their proliferation as described previously [14]. The blank was cells incubated in MTS solution in a complete endothelial cell growth medium. Results were presented as means ( \pm standard errors). Each experiment was performed in triplicate and repeated as already described.

\section{Culture of HUVECs with glucose and different treatments of pMSCs (conditioned medium and intercellular direct contact)}

HUVECs were cultured alone in a complete endothelial cell growth medium (Fig. 1a), or with $100 \mathrm{mM}$ glucose (Fig. 1b), or with $100 \mathrm{mM}$ glucose and 25\% CMpMSC (Fig. 1c). For the intercellular direct contact experiment (ICpMSC, Fig. 1d), HUVECs and pMSCs were separated by a transwell chamber membrane culture system (Cata$\log \#$ 657640, ThinCert ${ }^{\mathrm{tm}}$ Cell Culture Inserts $(0.4 \mu \mathrm{m})$; Greiner Bio-One, Germany). pMSCs were seeded on the reverse side of the membrane of the chamber while HUVECs were seeded on the upper side of the membrane as described previously [14]. Cells were cultured at a ratio of 1 HUVEC:1 pMSC in a complete endothelial cell growth medium in the presence of $100 \mu \mathrm{M}$ glucose and 


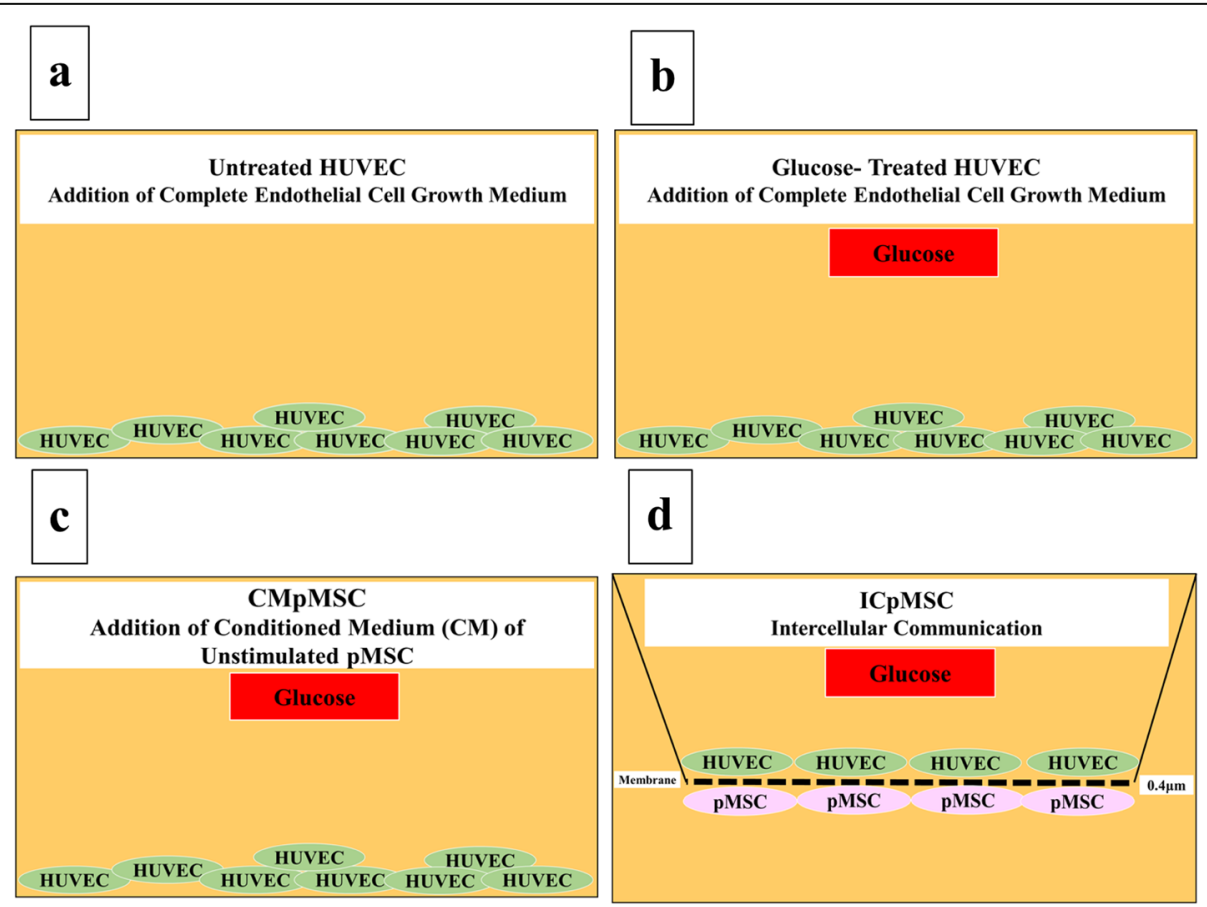

Fig. 1 HUVEC culture system consisted of HUVECs seeded on surface of six-well culture plate in complete HUVEC culture medium alone (untreated HUVECs) (a), or with $100 \mathrm{mM}$ glucose (b), or with $100 \mathrm{mM}$ glucose and 25\% conditioned medium (CM) obtained from unstimulated pMSCs (c), and ICPMSC (intercellular direct contact experiment) culture system consisted of pMSCS seeded on reverse side of membrane of chamber and HUVECS seeded on upper side of membrane (d). For ICpMSC, 0.4- $\mu \mathrm{m}$ pore size transwell chamber membranes were used. In ICpMSC culture system, cells cultured at a ratio of 1 HUVEC:1 pMSC in HUVEC culture medium in presence of $100 \mathrm{mM}$ glucose. In all culture systems, cells incubated for 24,48 , and $72 \mathrm{~h}$ at $37^{\circ} \mathrm{C}$ in a cell culture incubator. CMpMSC conditioned medium of unstimulated pMSCs, HUVEC human umbilical vein endothelial cell, pMSC placental mesenchymal stem cell

incubated as already described. After $72 \mathrm{~h}$, HUVEC were harvested with TrypLE ${ }^{\mathrm{si}}$ Express detachment solution and used in the adhesion, proliferation, migration, and invasion experiments (see later). HUVEC viability was determined using the Trypan blue exclusion assay. Each experiment was performed and repeated as already described. HUVECs cultured in complete endothelial cell growth medium without glucose or pMSCs were included as negative controls for all HUVECs cultured with glucose, and different treatments of pMSCs.

\section{HUVEC adhesion and proliferation using xCELLigence system}

The xCELLigence system (RTCA-DP version; Roche Diagnostics, Mannheim, Germany) was used as described previously $[14,15]$ to evaluate the adhesion and proliferation of HUVECs. The xCELLigence system is a real-time cell analyser that constantly monitors and records the changes in electrical impedance that arise from cellular events, and these changes are reported as an arbitrary cell index $[14,15]$. Briefly, $100 \mu \mathrm{l}$ complete endothelial cell growth medium was added to well in 16-well culture plates (Catalog \# 05469813001, E-Plate 16; Roche
Diagnostics), and the background impedance was then achieved as described previously $[14,15]$. Then, $2 \times 10^{5}$ HUVECs (initially cultured alone or co-cultured with $100 \mathrm{mM}$ glucose, or with $100 \mathrm{mM}$ glucose and CMpMSC, or with $100 \mathrm{mM}$ glucose and ICpMSC, as already described) were seeded in $100 \mu \mathrm{l}$ of complete endothelial cell growth medium in quadruplicate wells and equilibrium was achieved as described previously $[14,15]$. For the adhesion experiments, two treatment groups of HUVECs were used. Group one consisted of HUVECs pretreated as already described, and group two consisted of HUVECs seeded in wells of the E-Plate 16 containing complete endothelial cell growth medium with $100 \mathrm{mM}$ glucose or with $100 \mathrm{mM}$ glucose and $25 \%$ CMpMSC.

To record data, culture plates were placed in the xCELLigence system at $37{ }^{\circ} \mathrm{C}$ in a cell culture incubator. The HUVEC cell index was then monitored in real time for $72 \mathrm{~h}$. For data analysis, the xCELLigence software (version 1.2.1) was used. For cell adhesion, data were measured after $2 \mathrm{~h}$, and the value of cell index was then expressed as mean \pm standard error of the cell index. For cell proliferation, data were 
expressed as mean \pm standard error of the cell index normalized to the cell index recorded after $2 \mathrm{~h}$ (i.e. the adhesion time point). The rate of cell proliferation was determined by calculating the normalized cell index at 24, 48, and $72 \mathrm{~h}$. Each experiment was performed and repeated as already described.

\section{HUVEC migration using xCELLigence system}

The migration of HUVECs was evaluated using CIM migration plates (Catalog \# 05665825001; Roche Diagnostics) in the xCELLigence system as described previously $[14,15]$. The CIM plates have 16 migration wells that each consist of two chambers (upper and lower) separated by a membrane (polyethylene terephthalate) with a pore size of $8 \mu \mathrm{m}$. The membrane is in contact with microelectrodes. In the migration experiments, three treatment groups were used as illustrated in Fig. 2. Group one consisted of HUVECs seeded in the upper chamber containing HUVECs in serum-free medium alone, or supplemented with $100 \mathrm{mM}$ glucose, or with $100 \mathrm{mM}$ glucose and 25\% CMpMSC, while HUVEC medium was supplemented with 30\% FBS and added to the lower chamber. Group two consisted of HUVECs seeded in the upper chamber containing HUVEC serum-free medium, while HUVEC medium supplemented with $100 \mathrm{mM}$ glucose alone or with $100 \mathrm{mM}$ glucose and 25\% CMpMSC, and with HUVEC medium supplemented with $30 \%$ FBS, was added to the lower chamber. Group three consisted of HUVECs that were initially cultured alone, or co-cultured with $100 \mathrm{mM}$ glucose, or with $100 \mathrm{mM}$ glucose and CMpMSC, or with $100 \mathrm{mM}$ glucose and ICpMSC as already described. HUVECs were seeded in the upper chamber in HUVEC serum-free medium while HUVEC medium supplemented with $30 \%$ FBS was added to the lower chamber. Following the addition of $50 \mu \mathrm{l}$ pre-warmed media to the wells of the upper chamber and $160 \mu$ l endothelial cell growth medium containing 30\% FBS to the lower

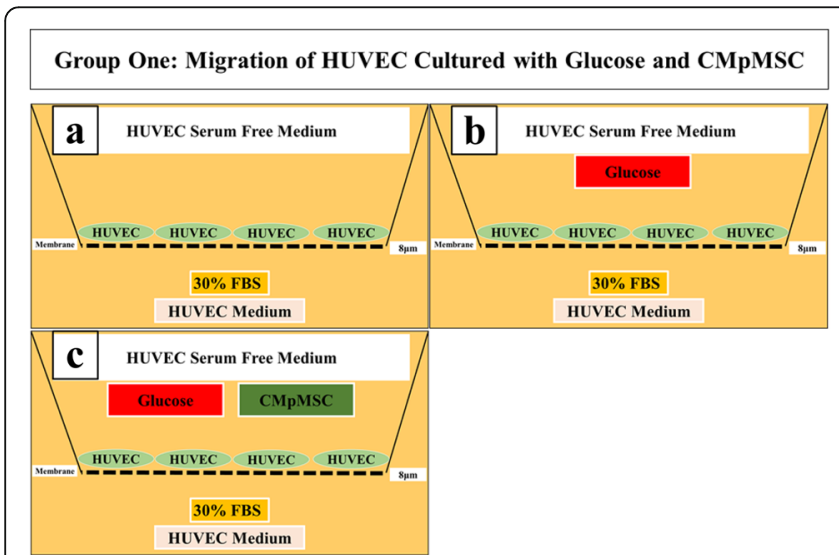

Group Two: Migration of HUVEC in response to Glucose and CMpMSC
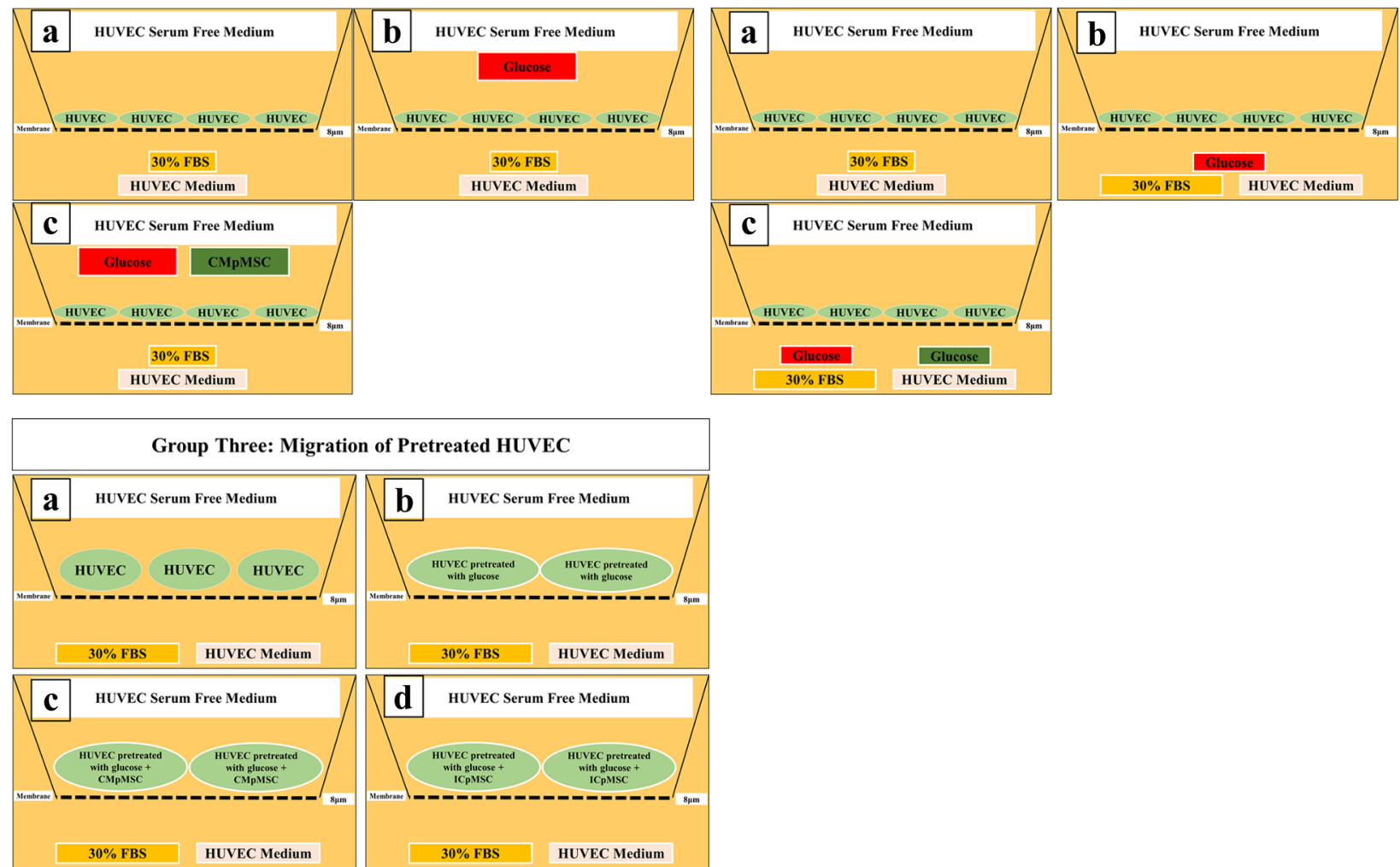

Fig. 2 HUVEC migration groups. Group 1: HUVECs cultured alone (a), or with $100 \mathrm{mM}$ glucose (b), or with $100 \mathrm{mM}$ glucose and 25\% conditioned medium obtained from unstimulated pMSC culture (CMpMSC) (c) in upper chamber of CIM migration plate, while HUVEC medium with 30\% FBS added to lower chamber. Group 2: HUVECs seeded in HUVEC serum-free medium in upper chamber of CIM migration plate while HUVEC medium with 30\% FBS (a), or with 100 mM glucose (b), or with 100 mM glucose and 20\% CMpMSC (b) added to lower chamber of migration plate. Group 3: HUVEC cultured alone (a), or with $100 \mathrm{mM}$ glucose (b), or with $100 \mathrm{mM}$ glucose and 25\% CMpMSC (c), or with pMSCs at ratio of 1 HUVEC:1 pMSC in intercellular direct contact experiment (ICPMSC) (d). Pretreated HUVECs seeded in HUVEC serum-free medium in upper chamber of CIM migration plate while HUVEC culture medium containing 30\% FBS added to lower chambers. CMpMSC conditioned medium of unstimulated pMSCs, FBS fetal bovine serum, HUVEC human umbilical vein endothelial cell, pMSC placental mesenchymal stem cell 
chamber, the plates were then locked in the RTCA DP device at $37{ }^{\circ} \mathrm{C}$ in a cell culture incubator for $1 \mathrm{~h}$ to obtain equilibrium, and a measurement step was then performed as described previously [14, 15]. Group one measured HUVEC migration, under the effect of glucose and CMpMSC added to the upper chamber of the plate. Group two measured HUVEC migration in response to glucose and CMpMSC added to the lower chamber of the plate. Group three measured HUVEC migration after cell exposure to glucose and different treatments of pMSCs. To initiate the experiment, HUVECs (above) were seeded at a density of $2 \times 10^{4}$ cells in the upper chamber in $100 \mu \mathrm{l}$, and the plates were then incubated for $30 \mathrm{~min}$ at RT to allow the cells to settle onto the membrane as described previously $[14,15]$. Each condition was performed in quadruplicate, and after equilibration the analyser was programmed to measure electrical impedance every $15 \mathrm{~min}$ for $24 \mathrm{~h}$. The impedance value of each well was automatically monitored by the xCELLigence system for a duration of $24 \mathrm{~h}$ and expressed as a CI value. Migration observed in the presence of $30 \%$ FBS, and with medium alone, served as positive and negative controls, respectively. Each experiment was performed and repeated as already described.

\section{pMSC effect on monocyte invasion of endothelial cell monolayer}

To evaluate the permeability of HUVECs, the ability of monocytes (THP-1) to invade a monolayer of HUVECs was evaluated using the E-Plate 16 and the xCELLigence system. In the invasion experiments, two treatment groups were used. Group one consisted of HUVECs seeded in wells of the E-Plate 16 containing complete endothelial cell growth medium with $100 \mathrm{mM}$ glucose alone, or with $100 \mathrm{mM}$ glucose and 25\% CMpMSC. Group two consisted of HUVECs initially cultured alone, or co-cultured with $100 \mathrm{mM}$ glucose alone, or with $100 \mathrm{mM}$ glucose and CMpMSC, or with $100 \mathrm{mM}$ glucose and ICpMSC. To initiate the invasion experiments, $2 \times 10^{4}$ HUVECs were seeded in a 16-well culture E-Plate as already described. When cells reached a growth plateau, monocytes $\left(10^{4}\right.$ cells $)$ were added to the HUVEC monolayer. Data for cell invasion were measured and expressed as a cell index with the value expressed as mean \pm standard error of the cell index. After $10 \mathrm{~h}$, the rate of cell invasion was determined by calculating the normalized cell index at the pausing time $(15-20 \mathrm{~h})$ of the growth of HUVECs. Five experiments were performed in triplicate using HUVECs and pMSCs as already described.

\section{Tube formation experiments}

Aliquots $(100 \mu \mathrm{l})$ of Matrigel $^{\oplus}$ Growth Factor Reduced (GFR) Basement (Catalog \# 354230; Corning, USA) were plated into individual wells of 96-well tissue culture plates (Becton Dickinson) and allowed to polymerize overnight at $37^{\circ} \mathrm{C}$ in a cell culture incubator. In the tube formation experiments, three treatment groups were used. Group one consisted of HUVECs cultured alone. Group two consisted of HUVECs cultured with $100 \mathrm{mM}$ glucose. Group three consisted of HUVECs cultured with $100 \mathrm{mM}$ glucose and 25\% CMpMSC. Group four consisted of HUVECs cultured with $100 \mathrm{mM}$ glucose and pMSCs. Varying pMSC:HUVEC ratios (1:30, 1:6, and 1:4) were used.

HUVECs were seeded at a density of $3 \times 10^{4}$ cells per well in a complete endothelial cell growth culture medium on the polymerized Matrigel. Following $14 \mathrm{~h}$, the tube network formed was observed under an inverted Nikon ECLIPSE Ti U microscope (Nikon, Japan). Photomicrographs were recorded using a Nikon DS-Qi1 camera and data were analysed with the software (Nikon, Japan). Experiments were carried out in triplicate and repeated as already described.

\section{RNA isolation, cDNA synthesis, and real-time polymerase chain reaction analysis}

The expression of 84 genes related to endothelial cell biology (Catalog \# PAHS-015ZD-24; Qiagen, Hilden, Germany) by HUVECs was determined using QuantiTect Primer Assay (Qiagen) in a real-time polymerase chain reaction (RT-PCR) as published previously [16]. Briefly, total RNA extracted from HUVECs initially co-cultured with $100 \mathrm{mM}$ glucose alone or in the presence of different treatments of pMSCs (CMpMSC and ICpMSC) for $72 \mathrm{~h}$ was isolated. cDNA was then synthesized and the real-time PCR reaction was performed in triplicate on the CFX96 real-time PCR detection system (BIO-RAD) as published previously [16]. To analyse the data, the CFX manager software (Bio-Rad, CA, USA) was used. The results were exported to Microsoft Excel for further analysis. The results were expressed as the fold change by calculating the $\Delta \Delta^{-2}$ values. The relative expression of an internal house-keeping gene as a loading control was used as provided in the kit. Experiments were performed in triplicate and repeated three times using HUVECs and pMSCs as already indicated.

\section{Flow cytometry}

Cells were characterized by flow cytometry as described previously [14]. Briefly, cells $\left(1 \times 10^{5}\right)$ were stained with monoclonal antibodies (Table 1) for $30 \mathrm{~min}$. Cells were then washed twice by adding cold PBS and centrifuged at $150 \times g$ for $5 \mathrm{~min}$ at $8{ }^{\circ} \mathrm{C}$. Unstained and isotype controls were used. Immunoreactivity to cell surface antibody markers or intracellular proteins was assayed by a 
BD FACS CANTO II (Becton Dickinson, NJ, USA) flow cytometer.

\section{Statistical analysis}

Data were analysed using an unpaired $t$ test, two tailed. These analyses were performed using GraphPad Prism 5. Results were considered to be statistically significant if $p<0.05$.

\section{Results}

\section{Isolation and characterization of pMSCs}

MSCs from the chorionic villi of human term placentae (pMSCs) were isolated and characterized using our published methodologies [11]. pMSCs at passage 2 were positive (>95\%) for MSC markers, were negative for haematopoietic markers, and were able to differentiate into adipocytes, chondrocytes, and osteocytes. These characteristics of pMSCs were consistent with our previous report [11]. Subsequently, pMSCs at passage 2 were used in all experiments.

\section{Glucose effects on the proliferative potential of pMSCs and HUVECs}

To evaluate the proliferative response of pMSCs to glucose, pMSCs were cultured alone, or with glucose, and the proliferation potential was then determined using the MTS assay. After 24, 48, and $72 \mathrm{~h}$ treatment with 200-2000 mM glucose, pMSC proliferation was significantly reduced $(p>0.05)$ as compared to glucose-untreated pMSCs (Fig. 3a-c), while the treatment with 20 $150 \mathrm{mM}$ glucose had no significant effect $(p>0.05)$ on pMSC proliferation at all culture time points $(24-72 \mathrm{~h})$ (Fig. 3a-c). The viability of pMSCs treated with 20 $200 \mathrm{mM}$ glucose was $>95 \%$ while the exposure of pMSCs to a concentration of glucose higher than

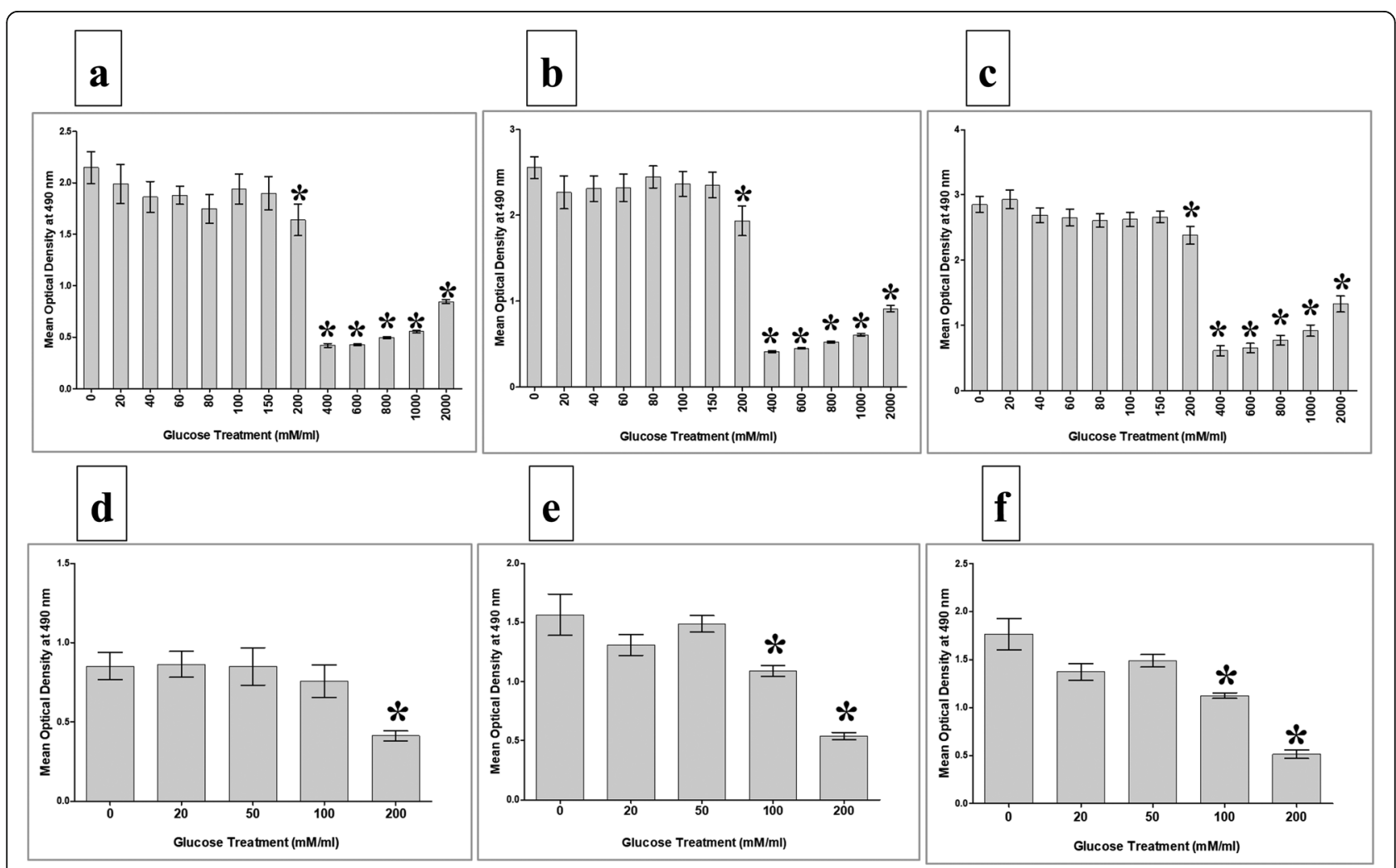

Fig. 3 Proliferation of pMSCs and HUVECs in response to various concentrations of glucose. MTS proliferation assay showed proliferation of pMSCs in response to 20,40,60,80,100, and $150 \mathrm{mM}$ glucose did not significantly change as compared to glucose-untreated pMSCs after $24 \mathrm{~h}$

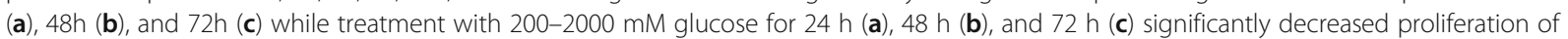
pMSCs as compared to glucose-untreated pMSCs. HUVEC proliferation in response to 20 and $50 \mathrm{mM}$ glucose did not significantly change as compared to glucose-untreated HUVECs after $24 \mathrm{~h}(\mathbf{d}), 48 \mathrm{~h}(\mathbf{e})$, and $72 \mathrm{~h}(\mathbf{f})$. Culture of HUVECs with $100 \mathrm{mM}$ glucose for $24 \mathrm{~h}$ (d) did not significantly change proliferation, but significantly decreased proliferation after $48 \mathrm{~h}(\mathbf{e})$ and $72 \mathrm{~h}$ (f) as compared to glucose-untreated pMSCs. HUVEC proliferation in response to $200 \mathrm{mM}$ glucose significantly reduced as compared to glucose-untreated HUVECs after $24 \mathrm{~h} \mathrm{(d),} 48 \mathrm{~h}$ (e), and $72 \mathrm{~h}$ (f). Each experiment performed in triplicate using pMSCs (passage 2) and HUVECs (passage 3-5) from five independent placentae and umbilical cord tissues. ${ }^{*} p<0.05$. Bars represent standard errors 
$200 \mathrm{mM}$ significantly reduced cell viability $(<50 \%)$ for all culture time points.

Next, we evaluated the proliferation of HUVECs in response to 20-2000 mM glucose. HUVEC proliferation did not significantly change $(p>0.05)$ after treating the cells with 20 and $50 \mathrm{mM}$ glucose as compared to glucose-untreated HUVECs for all culture time points (Fig. 3d-f), while the treatment with $100 \mathrm{mM}$ glucose significantly reduced HUVEC proliferation $(p<0.05)$ as compared to glucose-untreated HUVECs only after 48 and 72 h (Fig. 3e, f), but not after 24 h $(p>0.05$, Fig. 3d,). In contrast, the treatment with $200 \mathrm{mM}$ glucose significantly reduced HUVEC proliferation as compared to glucose-untreated HUVECs after 24, 48, and $72 \mathrm{~h}(p<0.05$, Fig. $3 \mathrm{~d}-\mathrm{f})$. The viability of HUVECs treated with 20, 50, and $100 \mathrm{mM}$ glucose was $>95 \%$ while the treatment with $200 \mathrm{mM}$ glucose reduced the viability to less than $50 \%$ for all culture time points. The exposure of HUVECs to glucose concentrations higher than $200 \mathrm{mM}$ significantly reduced $(<20 \%)$ the viability for all culture time points.

Based on the results obtained, the exposure time of $72 \mathrm{~h}$ and $100 \mathrm{mM}$ glucose were selected to evaluate the effect of glucose on the functions of HUVECs (proliferation, adhesion, migration, permeability, and tube network formation).

pMSCs and glucose modulate the proliferation of HUVECs To evaluate the effects of pMSCs on endothelial cell functions in response to glucose, the proliferation of HUVECs cultured with $100 \mathrm{mM}$ glucose alone, or with $100 \mathrm{mM}$ glucose and different treatments of pMSCs (CMpMSC and pMSCs), was examined using the MTS assay. The treatment of HUVEC with glucose, HUVEC proliferation significantly reduced after 48 and $72 \mathrm{~h}(p<$ $0.05)$, but not after $24 \mathrm{~h}(p>0.05)$, as compared to glucose-treated HUVECs (Fig. 4). The addition of CMpMSC to glucose-treated HUVEC significantly induced the proliferation of HUVECs after 48 and $72 \mathrm{~h}$ $(p<0.05)$, but not after $24 \mathrm{~h}$, as compared to glucose-treated HUVECs (Fig. 4a-c). However, the addition of pMSCs to glucose-treated HUVECs significantly induced the proliferation of HUVECs after 24, 48 , and $72 \mathrm{~h}(p<0.05)$ as compared to glucose-treated HUVECs (Fig. 4a-c). The addition of glucose to HUVECs in the presence of CMpMSC had no significant effect on HUVEC proliferation $(p>0.05)$ as compared to glucose-untreated HUVECs after all culture time points, while the addition of glucose to HUVECs in the presence of pMSCs significantly increased the proliferation of HUVECs after 24 and $48 \mathrm{~h}(p<0.05)$, but not after $72 \mathrm{~h} \quad(p>0.05)$, as compared to glucose-untreated HUVECs (Fig. 4a-c).

\section{The reversibility of HUVEC proliferation in response to glucose and pMSCs}

To evaluate the reversibility effect of pMSCs on the proliferation of glucose-treated HUVECs, HUVECs were initially cultured alone, or with $100 \mathrm{mM}$ glucose alone, or with $100 \mathrm{mM}$ glucose and different treatments of pMSCs (CMpMSC and ICpMSC) for $72 \mathrm{~h}$ and their proliferation was measured using the xCELLigence system. After 24 and $48 \mathrm{~h}$, the proliferation of glucose-pretreated HUVECs (100(Pre)) was not significantly changed $(p>0.05)$, but after $72 \mathrm{~h}$ it was significantly reduced $(p<0.05)$ as compared to glucose-untreated HUVECs (Fig. 4f). These data show that glucose has an irreversible inhibitory effect on HUVEC proliferation. The proliferation of HUVECs pretreated with glucose and CMpMSC $(\mathrm{PreCM}+100)$ did not significantly change $(p>0.05)$ after 24 and $48 \mathrm{~h}$, as compared to glucose-untreated HUVECs or glucose-pretreated HUVECs (100(Pre)) (Fig. 4d, e). However, proliferation was significantly reduced $(p<0.05)$ or unchanged $(p>0.05)$ after $72 \mathrm{~h}$ as compared to untreated HUVECs and glucose-pretreated HUVECs (100(Pre)), respectively (Fig. 4f). Therefore, the stimulatory effect of CMpMSC on glucose inhibiting HUVEC proliferation is reversible. The proliferation of HUVECs pretreated with glucose and ICpMSC (PreIC +100$)$ did not significantly change $(p>0.05)$ after 24 and $48 \mathrm{~h}$, as compared to glucose-untreated HUVECs and glucose-pretreated HUVECs (100(Pre)) (Fig. 4d, e). However, proliferation significantly increased $(p<0.05)$ or was unchanged $(p>0.05)$ after $72 \mathrm{~h}$ as compared to glucose-pretreated HUVECs (100(Pre)) and glucose-untreated HUVECs, respectively (Fig. 4f). These data show that the stimulatory effect of ICPMSC on glucose inhibition of HUVEC proliferation is irreversible.

\section{pMSCs and glucose effects on HUVEC adhesion}

To study the effects of pMSCs and glucose on the adhesion of HUVECs, two HUVEC treatment groups were evaluated as already described. After $2 \mathrm{~h}$, the adhesion of HUVECs treated with $100 \mathrm{mM}$ glucose alone (100), or with $100 \mathrm{mM}$ glucose and CMpMSC $(100+\mathrm{CM})$, did not significantly change as compared to glucose-untreated HUVECs $(p>0.05$, Fig. 5a). Similarly, after 2 h, the adhesion of HUVECs pretreated with $100 \mathrm{mM}$ glucose alone (100(Pre)), or with $100 \mathrm{mM}$ glucose and CMpMSC (PreCM + 100), or $100 \mathrm{mM}$ glucose and ICpMSC (PreIC + 100), were reduced but not statistically significant as compared to glucose-untreated HUVECs $(p>0.05$, Fig. $5 \mathrm{~b})$. In addition, the pretreatment of HUVECs with $100 \mathrm{mM}$ glucose and CMpMSC (PreCM + 100), or with $100 \mathrm{mM}$ glucose and ICpMSC (PreIC +100$)$, did not affect the adhesion of HUVECs as compared to glucose-pretreated HUVECs (100(Pre)) $(p>0.05$, Fig. 5b). 


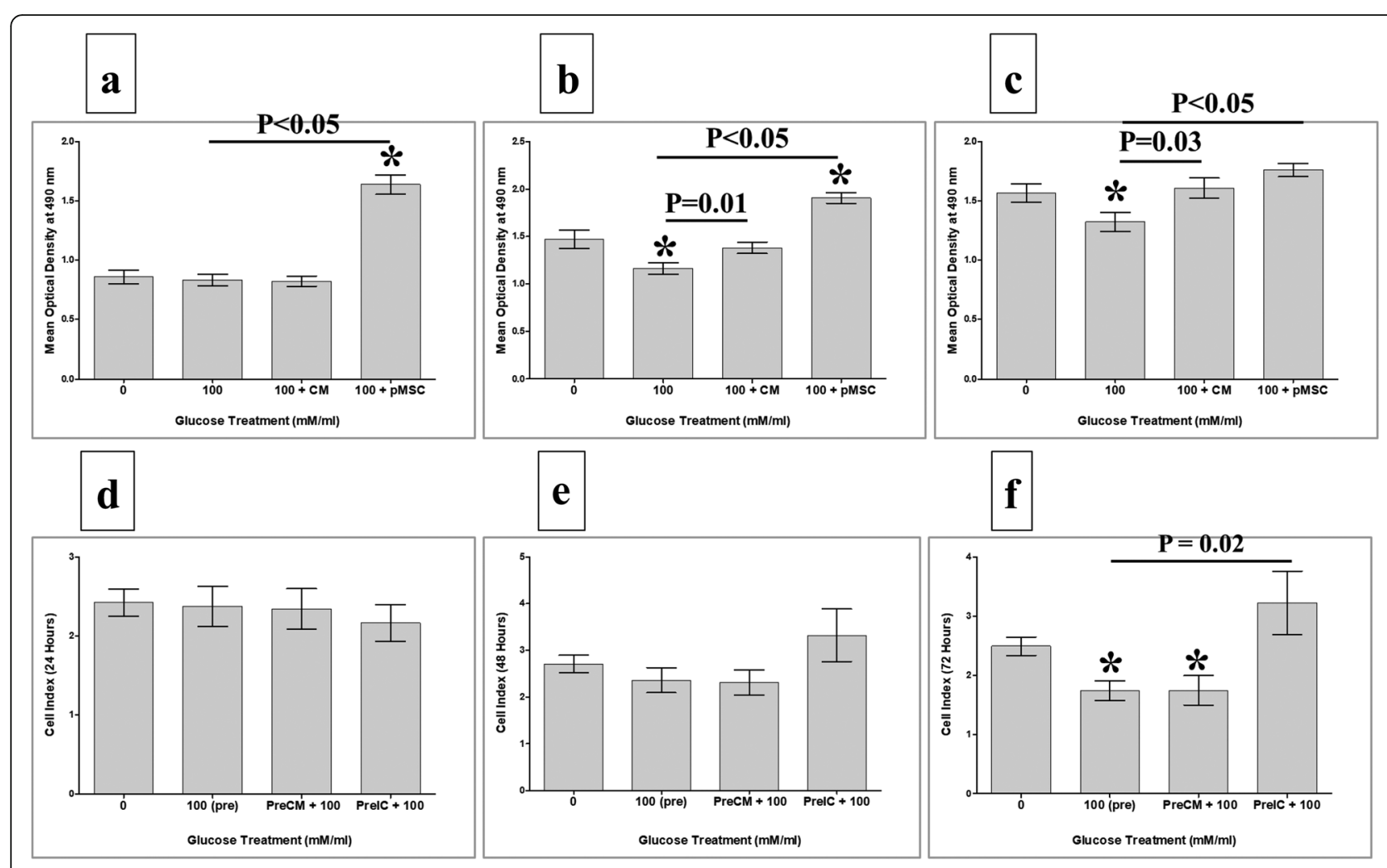

Fig. 4 HUVEC proliferation in response to glucose in presence of pMSCs, or after removing glucose and pMSCs, examined after 24, 48, and $72 \mathrm{~h}$ in MTS assay. In response to conditioned medium (CMPMSC), pMSCs had no significant effect on HUVEC proliferation in presence of glucose after $24 \mathrm{~h}$ as compared to untreated or glucose-treated HUVECs (a). CMpMSC significantly increased HUVEC proliferation in presence of glucose after $48 \mathrm{~h}(\mathbf{b})$ and $72 \mathrm{~h}(\mathbf{c})$, as compared to glucose-treated but not untreated HUVECs. Cell-cell contact assay showed that, compared to glucose-untreated or treated HUVECs, pMSCs significantly increased HUVEC proliferation in presence of glucose after $24 \mathrm{~h}(\mathbf{a})$ and $48 \mathrm{~h}$ (b), while after $72 \mathrm{~h}$ (c) pMSCs significantly increased HUVEC proliferation in presence of glucose, as compared to glucose-treated but not untreated HUVECS. HUVEC proliferation after removing effects of glucose and pMSCs. HUVECs initially cultured with $100 \mathrm{mM}$ glucose (100(pre)) in presence of different treatments of pMSCs (CMpMSC(PreCM + 100) and ICPMSC(PreCM + 100)) for $72 \mathrm{~h}$, and then used in proliferation assay using xCELLigence real-time cell analyser. After 24 and $48 \mathrm{~h}(\mathbf{d}, \mathbf{e})$, proliferation of HUVECs pretreated with glucose alone (100(pre)), or with CMpMSC (PreCM +100) or ICpMSC (PreCM + 100), did not significantly change as compared to glucose-untreated HUVEC $(p>0.05)$. As compared to glucose-treated HUVECs (100(pre)), proliferation of HUVECs pretreated with glucose and CMPMSC (PreCM + 100), or glucose and ICpMSC (PrelC +100 ), did not significantly change after 24 and $48 \mathrm{~h}(p>0.05)(\mathbf{d}, \mathbf{e})$. In contrast, proliferation of HUVECs pretreated with $100 \mathrm{mM}$ glucose alone (100(pre)), or with CMpMSC (PreCM + 100), significantly reduced after $72 \mathrm{~h}$ as compared to glucose-untreated HUVEC (f). When compared with glucose-treated HUVECs (100(pre)), proliferation of HUVECs pretreated with glucose and CMpMSC (PreCM + 100) did not significantly change after $72 \mathrm{~h}$ of culture. In contrast, proliferation of HUVECs pretreated with glucose and ICpMSC (PrelC +100 ) increased significantly after $72 \mathrm{~h}$ of culture as compared to glucose-treated but not untreated HUVECs (f). Each experiment performed in triplicate using HUVECs (passage 3-5) and pMSCs (passage 2) from five independent umbilical cord tissues and placentae, respectively. ${ }^{*} P$ value is significant $p<0.05$. Bars represent standard errors. pMSC placental mesenchymal stem cell

\section{pMSCs and glucose modulate HUVEC migration}

We further evaluated the migration of HUVECs exposed to $100 \mathrm{mM}$ glucose alone (100(in)) or to $100 \mathrm{mM}$ glucose and CMpMSC $(100+\mathrm{CM}($ in $))$ during the migration assay (migration group one, Fig. 2). After $24 \mathrm{~h}$ incubation with glucose (100(in)), HUVEC migration significantly reduced $(p<0.05)$ as compared to glucose-untreated HUVECs while the incubation with glucose and CMpMSC $(100+C M($ in $))$ had no significant effect $(p>0.05)$ on HUVEC migration as compared to glucose-untreated HUVECs (Fig. 6a). As compared to glucose-treated
HUVECs (100(in)), HUVEC migration in the presence of glucose and CMpMSC (100+CM(in)) significantly increased ( $p<0.05$, Fig. 6a).

We also examined the migration of HUVECs in response to $100 \mathrm{mM}$ glucose alone $(100$ (out)) or to $100 \mathrm{mM}$ glucose and CMpMSC $(100+\mathrm{CM}($ out $))$ (migration group two, Fig. 2). After 24 h, HUVEC migration in response to glucose alone $(100$ (out)) or to glucose and CMpMSC $(100+\mathrm{CM}($ out $))$ significantly reduced $(p<0.05)$ as compared to glucose-untreated HUVECs (Fig. 6b). In contrast, the migration of HUVECs in 
$\mathbf{a}$

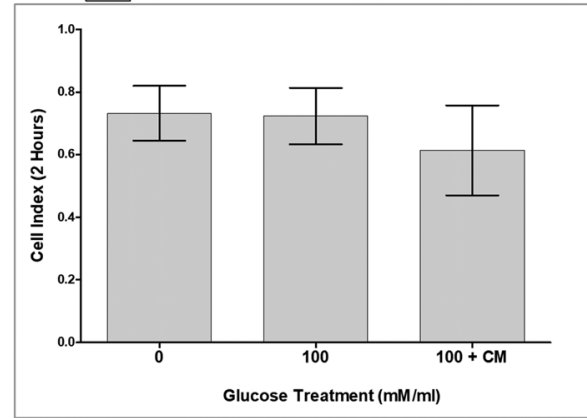

b

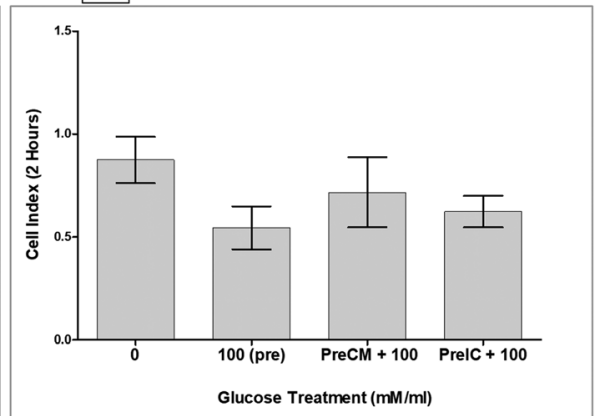

Fig. 5 HUVEC adhesion in response to glucose and pMSCs, or after removing effects of glucose and pMSCs. HUVECs cultured with 100 mM glucose alone (100), or with 25\% CMpMSC (100 + CM), and adhesion then measured using XCELLigence real-time cell analyser. After $2 \mathrm{~h}$, as compared to glucose-untreated HUVECs, HUVEC adhesion in presence of glucose alone (100), or with CMpMSC (100+CM), did not significantly change $(p>0.05)(\mathbf{a})$. Adhesion of HUVECs in presence of glucose and CMpMSC (100 + CM) did not significantly change as compared to glucosetreated HUVECs (100) after $2 \mathrm{~h}(p>0.05)$ (a). HUVECs pretreated with $100 \mathrm{mM}$ glucose (100(pre)) in presence of different pMSC treatments (CMpMSC (PreCM + 100) and ICpMSC (PrelC + 100)) were cultured in 16-well culture plate and adhesion measured as already indicated. After $2 \mathrm{~h}$, and as compared to glucose-untreated HUVECs, preteatment of HUVECs with glucose (100(pre)), or with glucose and CMpMSC (PreCM + 100), or with glucose and ICPMSC (PrelC +100$)$, did not significantly change $(p>0.05)(\mathbf{b})$. Adhesion of HUVECs in presence of glucose and CMpMSC (PreCM + 100), or glucose and ICpMSC (PrelC + 100), did not significantly change as compared to glucose-treated HUVECs (100(pre)) after $2 \mathrm{~h}$ $(p>0.05)(\mathbf{b})$. Each experiment performed in triplicate using HUVECs (passage 3-5) and pMSCs (passage 2) from five independent umbilical cord tissues and placentae, respectively. Bars represent standard errors

response to glucose and CMpMSC $(100+\mathrm{CM}($ out $))$ did not change $(p<0.05)$ as compared to glucosetreated HUVECs (100(out)) (Fig. 6b).

Next, we evaluated the effect of pretreatment with glucose and pMSCs as described in migration group three
(Fig. 2). After $24 \mathrm{~h}$, the migration of HUVECs pretreated with $100 \mathrm{mM}$ glucose alone (100(Pre)), or with $100 \mathrm{mM}$ glucose and CMpMSC $(100+\mathrm{CM}($ Pre $))$, or with $100 \mathrm{mM}$ glucose and ICpMSC (100 + IC(Pre)), significantly increased as compared to glucose-untreated HUVECs (Fig. 6c). In

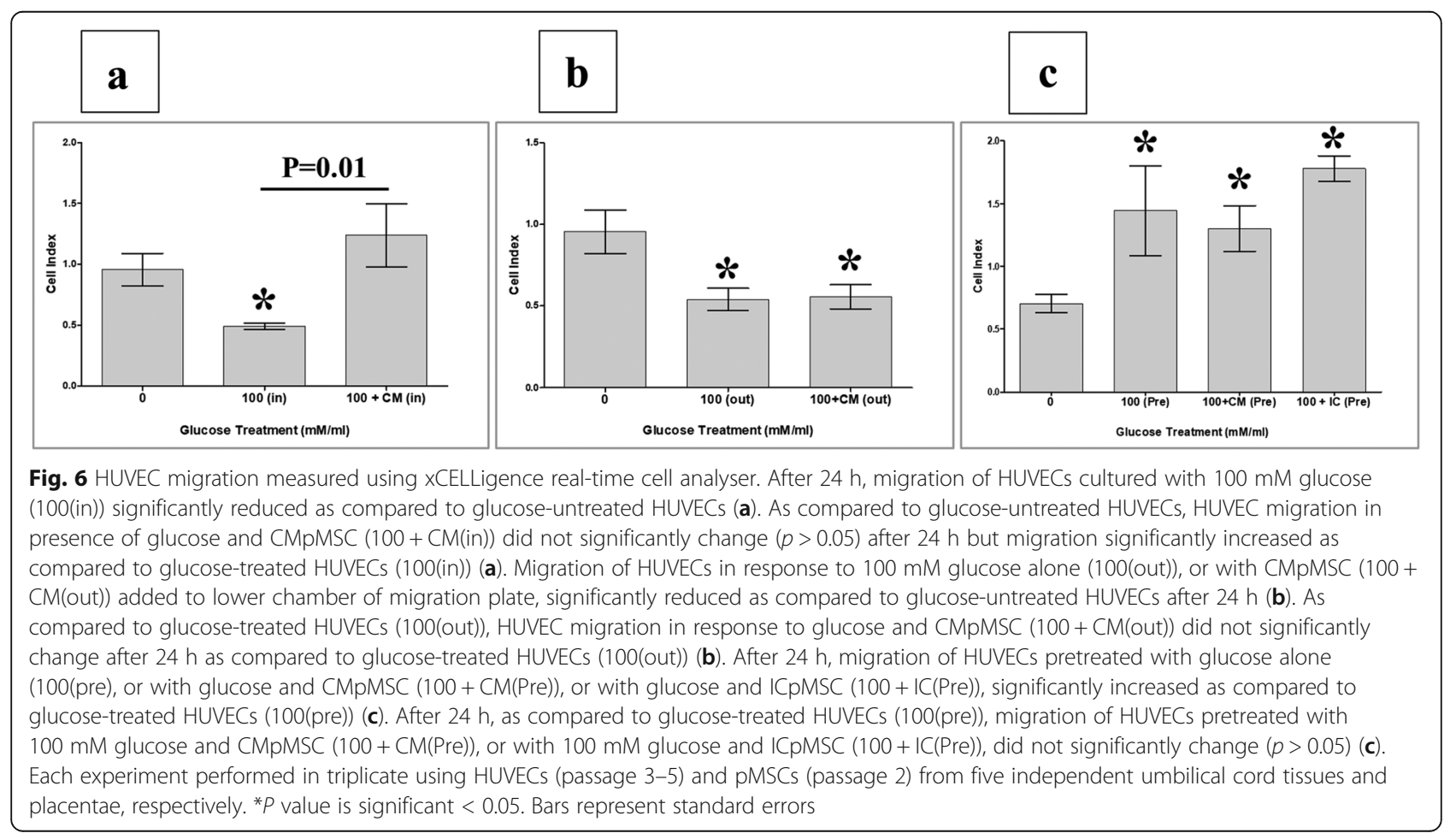


comparison with glucose-pretreated HUVECs (100(Pre)), the migration of HUVECs pretreated with glucose and CMpMSC $(100+\mathrm{CM}($ Pre $))$, or with glucose and ICpMSC $(100+\mathrm{IC}($ Pre $))$, was not significantly changed $(p<0.05)$ after 24 h (Fig. 6c).

\section{pMSCs reduce the effect of glucose on HUVEC permeability}

In the xCELLigence real-time system, increased invasion is defined as a reduction in the cell index due to the infiltration of the HUVEC monolayer by monocytes, causing detachment of HUVECs, while an increased cell index defines the reduction in cell invasion. The effect of glucose on the permeability of HUVECs in the presence or absence of CMpMSC was examined by adding monocytes to a monolayer of HUVECs and the invasion of monocytes through the HUVEC monolayer was then assessed by the xCELLigence real-time system. After $10 \mathrm{~h}$ and in the presence of glucose (100(in)), monocyte invasion of the HUVEC monolayer significantly increased $(p<0.05)$ as compared to glucose-untreated HUVECs (Fig. 7a). The addition of CMpMSC to glucose-cultured HUVECs $(100+\mathrm{CM}($ in $))$ significantly reduced $(p<0.05)$ monocyte invasion as compared to glucose-treated HUVECs (100(in)), but was not significantly changed $(p>0.05)$ as compared to glucose-untreated HUVECs (Fig. 7a).

We also evaluated the reversibility of monocyte invasion through the HUVEC monolayer by using HUVECs that were initially cultured alone, or with $100 \mathrm{mM}$ glucose alone, or with $100 \mathrm{mM}$ glucose and different treatments of pMSCs (CMpMSC and ICpMSC). The invasion of monocytes through the monolayer of HUVECs pretreated with glucose alone (100(pre)), or with CMpMSC (CM100(pre)), was not significantly changed as compared to glucose-untreated HUVECs, while the addition of ICpMSC (IC100(pre)) significantly reduced $(p<0.05)$ monocyte invasion as compared to glucose-treated HUVECs and untreated HUVECs (Fig. 7b).

\section{The effect of pMSCs on glucose inhibition of HUVEC tubule network formation in vitro}

To evaluate the effect of glucose on the ability of HUVECs to form tubule networks in vitro, HUVECs were seeded alone, or with $100 \mathrm{mM}$ glucose, or with $100 \mathrm{mM}$ glucose and different treatments of pMSCs (CMpMSC and pMSC) on a Matrigel-coated surface. After $14 \mathrm{~h}$, untreated HUVECs formed tube networks (Fig. 8a). The addition of CMpMSC to the HUVEC culture had no apparent effect on tubule network formation by HUVECs (Fig. 8b). However, the co-culture of HUVECs with pMSCs resulted in limited tubule network formation by HUVECs (Fig. 8c). The incubation of HUVECs with glucose had the most dramatic effect in that it completely inhibited HUVEC tubule network formation (Fig. 8d). The addition of CMpMSC to glucose-treated HUVECs reversed the inhibitory effect of glucose on HUVEC tubule network formation (Fig. 8e). Finally, the co-culture of HUVECs with pMSCs and glucose, HUVECs were unable to form extensive tubule networks (Fig. 8f).
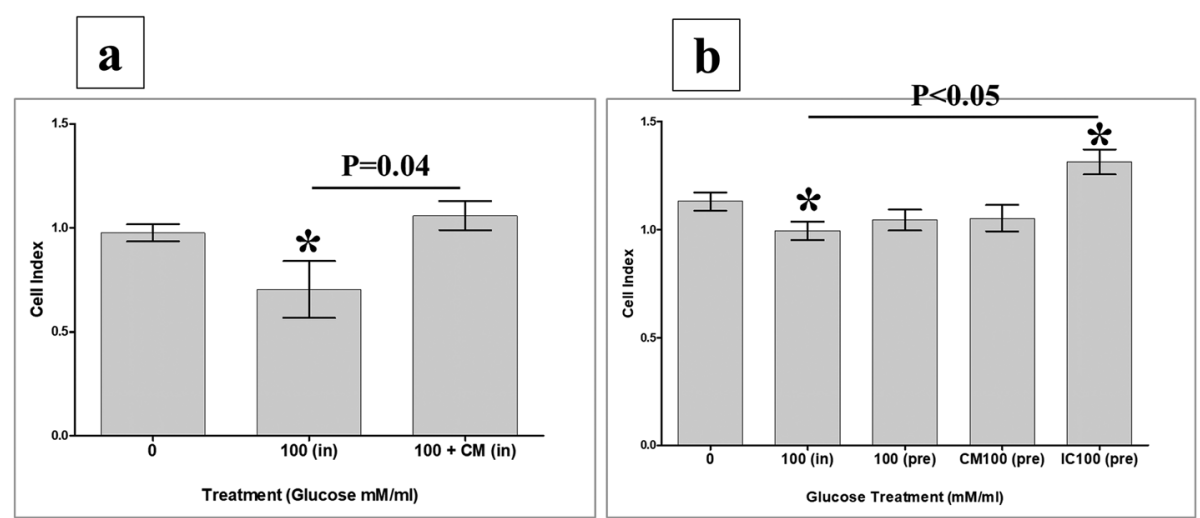

Fig. 7 HUVEC permeability under effects of glucose and pMSCs examined by adding monocytes to monolayer of HUVECS and assessing invasion of monocytes through HUVEC monolayer by xCELLigence real-time system. Increased invasion defined as reduction in cell index due to infiltration of HUVEC monolayer by monocytes, causing detachment of HUVECs, while increased cell index defines reduction in cell invasion. In presence of $100 \mathrm{mM} / \mathrm{ml}$ glucose (100(in)), monocyte invasion of HUVEC monolayer significantly increased after $10 \mathrm{~h}$ as compared to glucoseuntreated HUVECs (a). After $10 \mathrm{~h}$ and as compared to glucose-untreated HUVECs, monocyte invasion in presence of glucose and CMpMSC (100 + CM(in)) significantly reduced but not significantly changed as compared to glucose-untreated HUVECs (a). Monocyte invasion through monolayer of HUVECs pretreated with glucose alone (100(pre)), or with glucose and CMPMSC (100 + CM(pre)), not significantly changed after $10 \mathrm{~h}$ as compared to glucose-untreated HUVECs, while addition of ICPMSC (100 + IC(pre)) significantly reduced monocyte invasion as compared to glucose-treated (100(pre)) or untreated HUVECs (b). Each experiment performed in triplicate using HUVECs (passage 3-5) and pMSCs (passage 2) from five independent umbilical cord tissues and placentae, respectively. ${ }^{*} P$ value is significant $<0.05$. Bars represent standard errors 

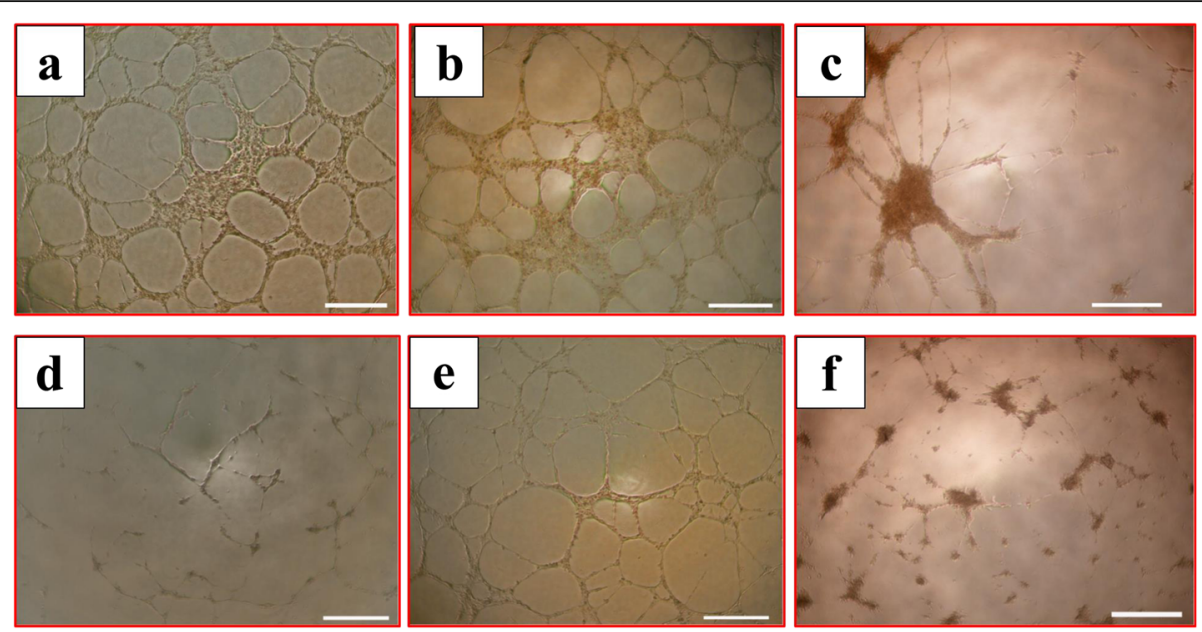

Fig. 8 HUVEC tubule formation in presence of glucose and pMSCs. After $14 \mathrm{~h}$, glucose-untreated pMSCs (a) and HUVECs cultured with 25\% CMpMSC (b) able to form tube networks. HUVECs cultured with pMSCs alone did not form extensive tubule networks (c), and with $100 \mathrm{mM}$ glucose alone (d) were unable to form tube networks. HUVECs cultured with $100 \mathrm{mM}$ glucose and 25\% CMpMSC (e) able to form tube networks, while culturing HUVECs with $100 \mathrm{mM}$ glucose and pMSCs (f) failed to form extensive tube networks. Each experiment performed in triplicate using HUVECs (passage 3-5) and pMSCs (passage 2) from five independent umbilical cord tissues and placentae, respectively

pMSCs modulate the effect of glucose on the expression of genes important in endothelial cell functions

The expression of genes mediating endothelial cell functions was studied after culturing endothelial cells with glucose in the presence or absence of pMSCs for $72 \mathrm{~h}$, and then analysed and assessed using the real-time PCR assay. Results show that pMSCs modulated glucose effects on endothelial cell expression of genes underlying many of the endothelial cell functional activities, including survival, apoptosis, injury, inflammation, angiogenesis, permeability, and leukocyte infiltration, as compared to glucose-treated endothelial cells (Tables 2, 3, 4, 5, 6, and 7).

\section{Discussion}

In diabetes, hyperglycaemia stimulates the production of $\mathrm{H}_{2} \mathrm{O}_{2}$ in the endothelium that contributes to the development of endothelial injury and the development of thrombosis [2-8]. Recently, we reported the ability of pMSCs to protect endothelial cells from injury induced by $\mathrm{H}_{2} \mathrm{O}_{2}$ [14]. Therefore, pMSCs are potential

Table 2 pMSCs modulate expression of genes involved in endothelial cell (EC) survival, apoptosis, injury, and inflammation

\begin{tabular}{|c|c|c|c|c|c|c|}
\hline Number & $\begin{array}{l}\text { Gene } \\
\text { symbol }\end{array}$ & Gene full name & $\begin{array}{l}\text { Glucose mean } \\
\Delta \Delta^{-2} \text { value }\end{array}$ & $\begin{array}{l}\text { Glucose }+ \text { CMpMSC } \\
\text { mean } \Delta \Delta^{-2} \text { value }\end{array}$ & $\begin{array}{l}\text { Fold change, glucose vs } \\
\text { glucose + CMpMSC } \\
(p<0.05)\end{array}$ & $\begin{array}{l}\text { Biological } \\
\text { activity }\end{array}$ \\
\hline 1 & CAV1 & Caveolin-1 & 6 & 3 & 2-fold $\downarrow$ & \multirow{2}{*}{$\begin{array}{l}\text { Inhibits EC } \\
\text { proliferation }\end{array}$} \\
\hline 2 & COL18A1 & Collagen, type XVIII, alpha 1 & 463 & 4 & 115 -fold $\downarrow$ & \\
\hline 3 & $P R O C R$ & Protein C receptor, endothelial & 0.61 & 9.11 & 14.93-fold $\uparrow$ & \multirow{4}{*}{$\begin{array}{l}\text { Induces EC } \\
\text { survival }\end{array}$} \\
\hline 4 & $F 2 R$ & Protease-activated receptor-1 & 1.8 & 104.45 & 58.02 -fold $\uparrow$ & \\
\hline 5 & EDN1 & Endothelin-1 & 1 & 6 & 6 -fold $\uparrow$ & \\
\hline 6 & TYMP & Thymidine phosphorylase & 5 & 219 & 43.80-fold $\uparrow$ & \\
\hline 7 & ENG & Endoglin & 60.47 & 1.79 & 33.78-fold $\downarrow$ & \multirow[t]{4}{*}{ Induces EC injury } \\
\hline 8 & $C \times 3 C L 1$ & Chemokine ligand 1 & 6.85 & 2.55 & 2.68-fold $\downarrow$ & \\
\hline 9 & F3 & Coagulation factor III, tissue factor & 7.17 & 1.39 & 5.15-fold $\downarrow$ & \\
\hline 10 & THBD & Thrombomodulin & 131.78 & 8.52 & 15.46-fold $\downarrow$ & \\
\hline 11 & 113 & Interleukin 3 & 47.75 & 0.0006 & 79,583.3-fold $\downarrow$ & \multirow{3}{*}{$\begin{array}{l}\text { Induces EC } \\
\text { inflammation }\end{array}$} \\
\hline 12 & ALOX5 & Arachidonate 5-lipoxygenase & 103.45 & 17.62 & 53.05-fold $\downarrow$ & \\
\hline 13 & FLT1 & $\begin{array}{l}\text { Vascular endothelial growth factor } \\
\text { receptor } 1\end{array}$ & 7.14 & 2.75 & 2.59-fold $\downarrow$ & \\
\hline
\end{tabular}


Table 3 pMSCs modulate expression of genes mediating endothelial cell (EC) angiogenesis

\begin{tabular}{|c|c|c|c|c|c|c|}
\hline Number & Gene symbol & Gene full name & Glucose $\Delta \Delta^{-2}$ value & $\begin{array}{l}\text { Glucose + CMpMSC } \\
\Delta \Delta^{-2} \text { value }\end{array}$ & $\begin{array}{l}\text { Fold change, glucose vs } \\
\text { glucose + CMpMSC } \\
(p<0.05)\end{array}$ & $\begin{array}{l}\text { Biological } \\
\text { activity }\end{array}$ \\
\hline 1 & $A G T$ & Angiotensinogen & 3.3 & 0.004 & 825-fold $\downarrow$ & \multirow{2}{*}{$\begin{array}{l}\text { Inhibits EC } \\
\text { angiogenesi }\end{array}$} \\
\hline 2 & COL18A1 & Collagen, type XVIII, alpha 1 & 463 & 4 & 115-fold $\downarrow$ & \\
\hline 3 & $F 2 R$ & Protease-activated receptor-1 & 1.8 & 104.45 & 58.02 -fold $\uparrow$ & \multirow{4}{*}{$\begin{array}{l}\text { Induces EC } \\
\text { angiogenesi }\end{array}$} \\
\hline 4 & ICAMI & Intercellular adhesion molecule 1 & 11.5 & 23.85 & 2.07-fold $\uparrow$ & \\
\hline 5 & PGF & Placental growth factor & 3.21 & 22.27 & 6.93-fold $\uparrow$ & \\
\hline 6 & CCL2 & Monocyte chemotactic protein-1 (MCP-1) & 17.72 & 35.67 & 2.01 -fold $\uparrow$ & \\
\hline 7 & EDN1 & Endothelin-1 & 1 & 6 & 6-fold $\uparrow$ & \multirow{3}{*}{$\begin{array}{l}\text { Induces EC } \\
\text { migration }\end{array}$} \\
\hline 8 & PF4 & Platelet factor 4 & 0.79 & 3.94 & 4.98-fold $\uparrow$ & \\
\hline 9 & ICAMI & Intercellular adhesion molecule 1 & 11.5 & 23.85 & 2.07-fold $\uparrow$ & \\
\hline
\end{tabular}

CMpMSC conditioned medium of unstimulated pMSCs, pMSC placental mesenchymal stem cell, $\downarrow$ decrease, $\uparrow$ increase

candidates for cellular therapy to repair endothelial dysfunction and prevent complications associated with diabetes, such as thrombosis and atherosclerosis. Here, we examined the ability of pMSCs to protect the functions of endothelial cells from injury induced by glucose; an oxidative stress mediator.

First, we showed that pMSCs retain their survival and proliferation potentials in a glucose environment, which contains up to $200 \mathrm{mM}$ glucose (Fig. 3a-c). pMSCs are usually found in close and continuous contact with fetal circulation, and therefore are exposed to relatively low levels of oxidative stress mediators $[17,18]$. This may explain the inability of pMSCs to overcome the toxicity of glucose at high concentrations since we recently reported that exposure of pMSCs to a concentration of $\mathrm{H}_{2} \mathrm{O}_{2}$ higher than $200 \mu \mathrm{M}$ is toxic [14]. These data indicate that pMSCs can resist the effects of glucose and maintain their normal function, but only up to a certain concentration, after which glucose becomes toxic.

Next, we demonstrated the ability of endothelial cells to survive in a glucose environment, but at a concentration of up to $100 \mathrm{mM}$ glucose. At this concentration, the viability of endothelial cells was higher than $95 \%$, but with reduced proliferation potential (Fig. 3d-f). This inhibitory effect of glucose on endothelial cell proliferation $[19,20]$ was reversed by pMSCs (Fig. $4 \mathrm{a}-\mathrm{c}$ ). Interestingly, pMSCs showed a dual effect on the reversibility of glucose-treated endothelial cells (Fig. 4f). Molecules produced by unstimulated pMSCs (CMpMSC) have a reversible effect on glucose-treated endothelial cells while the intercellular direct contact (ICpMSC) with endothelial cells showed an irreversible stimulatory effect on glucose-treated endothelial cells (Fig. 4f). These data provide evidence that pMSCs protect endothelial cell proliferation from the negative effect of glucose. This is supported by the finding that pMSCs modify the expression of genes mediating endothelial cell proliferation. CMpMSC and ICpMSC reduced endothelial cell expression of antiproliferative genes including CAV1 [21] and COL18A1 [22] (Tables 2 and 5). In addition, ICpMSC induced endothelial cell expression of pro-proliferative genes including PLAT [20] and PDGFRA [23] (Table 5). This protective role of pMSCs was further confirmed by the ability of CMpMSC to reverse the inhibitory effect of glucose on endothelial cell migration [24] (Fig. 6a), and this stimulatory effect of pMSCs (CMpMSC and ICpMSC) on endothelial cell migration is irreversible (Fig. 6c). One

Table 4 pMSCs modulate expression of genes mediating endothelial cell (EC) permeability and leukocyte infiltration of ECs

\begin{tabular}{|c|c|c|c|c|c|c|}
\hline Number & Gene symbol & Gene full name & $\begin{array}{l}\text { Glucose } \\
\Delta \Delta^{-2} \text { value }\end{array}$ & $\begin{array}{l}\text { Glucose + CMpMSC } \\
\Delta \Delta^{-2} \text { value }\end{array}$ & $\begin{array}{l}\text { Fold change, glucose } \\
\text { vs glucose + CMpMSC } \\
(p<0.05)\end{array}$ & Biological activity \\
\hline 1 & ALOX5 & Arachidonate 5-lipoxygenase & 103.45 & 17.62 & 53.05-fold $\downarrow$ & \multirow[t]{2}{*}{ Induces EC permeability } \\
\hline 2 & ICAMI & Intercellular adhesion molecule 1 & 11.5 & 23.85 & 2.07-fold $\uparrow$ & \\
\hline 3 & NPR1 & Atrionatriuretic peptide receptor A & 1.16 & 3.79 & 3.26 -fold $\uparrow$ & \multirow[t]{2}{*}{ Inhibits EC permeability } \\
\hline 4 & CAV1 & Caveolin-1 & 5.87 & 3.16 & 1.85 -fold $\downarrow$ & \\
\hline 5 & ENG & Endoglin & 60.47 & 1.79 & 33.78-fold $\downarrow$ & \multirow{4}{*}{$\begin{array}{l}\text { Induces leukocyte } \\
\text { infiltration }\end{array}$} \\
\hline 6 & VCAM1 & Vascular cell adhesion molecule 1 & 64.03 & 1.79 & 35.77-fold $\downarrow$ & \\
\hline 7 & SELL & Selectin $\mathrm{L}$ & 22.05 & 35.91 & 1.62 -fold $\uparrow$ & \\
\hline 8 & SELE & E-selectin & 22.05 & 35.91 & 1.62 -fold $\uparrow$ & \\
\hline
\end{tabular}

CMpMSC conditioned medium of unstimulated pMSCs, pMSC placental mesenchymal stem cell, $\downarrow$ decrease, $\uparrow$ increase 
Table 5 pMSCs modulate expression of genes involved in endothelial cell (EC) survival, apoptosis, injury, fibrosis formation, and inflammation

\begin{tabular}{|c|c|c|c|c|c|c|}
\hline Number & Gene symbol & Gene full name & Glucose $\Delta \Delta^{-2}$ value & $\begin{array}{l}\text { Glucose }+ \text { ICpMSC } \\
\Delta \Delta^{-2} \text { value }\end{array}$ & $\begin{array}{l}\text { Fold change, glucose } \\
\text { vs. glucose }+ \text { ICpMSC } \\
(p<0.05)\end{array}$ & Biological activity \\
\hline 1 & PLAT & Plasminogen activator, tissue & 4.52 & 247.12 & 54.67 -fold $\uparrow$ & \multirow{2}{*}{$\begin{array}{l}\text { Induces EC } \\
\text { proliferation }\end{array}$} \\
\hline 2 & PDGFRA & $\begin{array}{l}\text { Platelet-derived growth factor receptor, } \\
\text { alpha polypeptide }\end{array}$ & 38 & 76 & 2 -fold $\uparrow$ & \\
\hline 3 & CAV1 & Caveolin-1 & 6 & 2 & 3-fold $\downarrow$ & \multirow{2}{*}{$\begin{array}{l}\text { Inhibits EC } \\
\text { proliferation }\end{array}$} \\
\hline 4 & COL18A1 & Collagen, type XVIII, alpha 1 & 463 & 19 & 24-fold $\downarrow$ & \\
\hline 5 & $P R O C R$ & Protein C receptor, endothelial & 0.61 & 7.69 & 12.6-fold $\uparrow$ & \multirow[t]{8}{*}{ Induces EC survival } \\
\hline 6 & $F 2 R$ & Protease-activated receptor-1 & 1.8 & 10.91 & 6.06-fold $\uparrow$ & \\
\hline 7 & TGFB1 & Transforming growth factor beta 1 & 0.96 & 37.26 & 138-fold $\uparrow$ & \\
\hline 8 & $B C L 2 L 1$ & BCL2-like 1 & 1.4 & 140.43 & 100.3-fold $\uparrow$ & \\
\hline 9 & MMP1 & Matrix metallopeptidase 1 & 1.06 & 24 & 22.64-fold $\uparrow$ & \\
\hline 10 & $K D R$ & $\begin{array}{l}\text { Vascular endothelial growth factor } \\
\text { receptor } 3 \text { (VEGFR3) }\end{array}$ & 0.62 & 50.83 & 81.92 -fold $\uparrow$ & \\
\hline 11 & SPHK1 & Sphingosine kinase 1 & 1330.29 & $1,156,189.43$ & 869.12-fold $\uparrow$ & \\
\hline 12 & TNFSF10 & $\begin{array}{l}\text { TNF-related apoptosis-inducing } \\
\text { ligand (TRAIL) }\end{array}$ & 1.65 & 1788.25 & 1083-fold $\uparrow$ & \\
\hline 13 & FASLG & Fas ligand & $18,254.05$ & 9.84 & 1855.08-fold $\downarrow$ & $\begin{array}{l}\text { Induces EC } \\
\text { apoptosis }\end{array}$ \\
\hline 14 & ENG & Endoglin & 60.47 & 1.89 & 31.99-fold $\downarrow$ & \multirow[t]{3}{*}{ Induces EC injury } \\
\hline 15 & AGTR1 & Angiotensin I| receptor, type 1 & 2366.34 & 227.48 & 10.4-fold $\downarrow$ & \\
\hline 16 & THBD & Thrombomodulin & 131.78 & 10.19 & 12.93-fold $\downarrow$ & \\
\hline 17 & $1 L 3$ & Interleukin 3 & 47.75 & 0.59 & 80.93-fold $\downarrow$ & \multirow{3}{*}{$\begin{array}{l}\text { Induces EC } \\
\text { inflammation }\end{array}$} \\
\hline 18 & ALOX5 & Arachidonate 5-lipoxygenase & 103.45 & 0.82 & 126.15-fold $\downarrow$ & \\
\hline 19 & FLT1 & $\begin{array}{l}\text { Vascular endothelial growth } \\
\text { factor receptor } 1\end{array}$ & 7.14 & 1.96 & 3.64-fold $\downarrow$ & \\
\hline
\end{tabular}

ICPMSC intercellular direct contact experiment, pMSC placental mesenchymal stem cell, TNF tumour necrosis factor, $\downarrow$ decrease, $\uparrow$ increase

possibility is that pMSCs induce glucose-treated endothelial cell migration by upregulating their expression of pro-migratory genes including EDN1 [25], PF4 [26], ICAM1 [23], and SPHK1 [27] (Tables 3 and 6).

We previously reported that pMSCs produce many molecules with survival, pro-proliferative, and migratory activities, such as $I L-6$ [28], $I L-8[29,30], I L-10$ [31], IL-11 [32], and PDGF-R $\beta$ [33]. These molecules potentially mediate the pMSC protective effects on endothelial cells treated with glucose. However, future functional studies are essential to elucidate the detailed molecular mechanism.

Migration is an important early step in endothelial cell biology that is followed by angiogenesis [15]. In this study, CMpMSC do not interfere with the angiogenic activity of endothelial cells (Fig. 8b). Importantly, CMpMSC reversed the anti-angiogenic effect of glucose [20] on endothelial cells (Fig. 8d, e). This protective function of CMpMSC on endothelial cell angiogenesis could be mediated by a number of angiogenic genes. CMpMSC reduced glucose-treated endothelial cell expression of various anti-angiogenic genes including $A G T$
[34] and COL18A1 [22] (Table 3). In addition, CMpMSC increased glucose-treated endothelial cell expression of various pro-angiogenic genes including $F 2 R$ [35], ICAM1 [23], PGF [36], and CCL2 [37] (Table 3). In contrast, ICpMSC inhibited endothelial cell angiogenesis and did not prevent the anti-angiogenic effect of glucose on endothelial cells (Fig. 8f). This anti-angiogenic effect of pMSCs is possibly mediated by a number of anti-angiogenic genes including TIMP-1 [38], PF4 [26], and CASP1 [39] (Table 6), although ICpMSC also reduced glucose-treated endothelial cell expression of anti-angiogenic genes including $A G T$ [34] and COL18A1 [22] (Table 6) and induced the expression of pro-angiogenic genes including F2R [35], ICAM1 [23], PGF [36], CCL2 [37], and PTGS2 [40] by endothelial cells (Table 6). These data provide evidence that pMSCs have dual effects (i.e. "a double-edged sword") on the angiogenic activity of endothelial cells as was previously reported for the immunomodulatory properties of bone marrow-derived MSCs [41]. Supporting evidence comes from the ability of pMSCs to produce both anti-angiogenic molecules, such as $I L-12$ [42], and 
Table 6 pMSCs modulate expression of genes mediating endothelial cell (EC) angiogenesis

\begin{tabular}{|c|c|c|c|c|c|c|}
\hline Number & $\begin{array}{l}\text { Gene } \\
\text { symbol }\end{array}$ & Gene full name & $\begin{array}{l}\text { Glucose } \Delta \Delta^{-2} \\
\text { value }\end{array}$ & $\begin{array}{l}\text { Glucose }+ \text { ICpMSC } \\
\Delta \Delta^{-2} \text { value }\end{array}$ & $\begin{array}{l}\text { Fold change, glucose } \\
\text { vs glucose }+ \text { ICpMSC } \\
(p<0.05)\end{array}$ & Biological activity \\
\hline 1 & TIMP1 & TIMP metallopeptidase inhibitor 1 & 2.28 & 6.7 & 2.93-fold $\uparrow$ & \multirow{5}{*}{$\begin{array}{l}\text { Inhibits EC } \\
\text { angiogenesis }\end{array}$} \\
\hline 2 & CASP1 & Apoptosis-related cysteine peptidase & 0.01 & 8.97 & 897-fold $\uparrow$ & \\
\hline 3 & PF4 & Platelet factor 4 & 0.79 & 3.54 & 4.48-fold $\uparrow$ & \\
\hline 4 & $A G T$ & Angiotensinogen & 3.3 & 0.54 & 6.1-fold $\downarrow$ & \\
\hline 5 & COL18A1 & Collagen, type XVIII, alpha 1 & 463 & 19 & 24-fold $\downarrow$ & \\
\hline 6 & $F 2 R$ & Protease-activated receptor-1 & 1.8 & 10.91 & 6.06 -fold $\uparrow$ & \multirow{5}{*}{$\begin{array}{l}\text { Induces EC } \\
\text { angiogenesis }\end{array}$} \\
\hline 7 & ICAMI & Intercellular adhesion molecule 1 & 11.5 & 642.79 & 55.89-fold $\uparrow$ & \\
\hline 8 & PGF & Placental growth factor & 3.21 & 178.53 & 55.56 -fold $\uparrow$ & \\
\hline 9 & $C C L 2$ & $\begin{array}{l}\text { Monocyte chemotactic protein-1 } \\
\text { (MCP-1) }\end{array}$ & 17.72 & 44.51 & 2.52 -fold $\uparrow$ & \\
\hline 10 & PTGS2 & Cyclooxygenase (COX) & 1.9 & 3.84 & 2.02 -fold $\uparrow$ & \\
\hline 11 & SPHK1 & Sphingosine kinase 1 & 1330.29 & $1,156,189.43$ & 869-fold $\uparrow$ & \multirow[t]{3}{*}{ Induces EC migration } \\
\hline 12 & PF4 & Platelet factor 4 & 0.79 & 3.54 & 4.48-fold $\uparrow$ & \\
\hline 13 & ICAMI & Intercellular adhesion molecule 1 & 11.5 & 642.79 & 55.89 -fold $\uparrow$ & \\
\hline
\end{tabular}

ICpMSC intercellular direct contact experiment, pMSC placental mesenchymal stem cell, $\downarrow$ decrease, $\uparrow$ increase

pro-angiogenic molecules such as $I L-8$ [29] and $I L-10$ [43]. Our data indicate that the nature of pMSC treatments determines the type of angiogenic activity of pMSCs on endothelial cells. However, future study is essential to determine what factors determine whether the effects are pro-angiogenic or anti-angiogenic.

The exposure of endothelial cells to high levels of glucose increases their permeability [44]. This in turn enhances the infiltration of monocytes through endothelium as reported previously [44]. pMSCs reduced the stimulatory effect of glucose on monocyte infiltration through the endothelial cell monolayer, which suggests that pMSCs reduce the stimulatory effect of glucose on endothelial cell permeability (Fig. 7a). The preconditioning of endothelial cells with glucose also increased endothelial cell permeability, an effect that was reversed by ICpMSC but not by CMpMSC (Fig. 7b). This further shows the dual effects of pMSCs on the reversibility of endothelial cells in the presence of glucose. These data further support a protective effect of pMSCs on endothelial cells. The addition of pMSCs (CMpMSC or ICpMSC) to glucose-treated endothelial cells downregulated and upregulated endothelial cell expression of pro-permeability genes (i.e. ALOX5 [45] and NPPB [46]) and the anti-permeability genes (i.e. NPR1 [47]), respectively (Tables 4 and 7). In addition, pMSCs reduced the glucose stimulatory effect on endothelial cell expression of genes (ENG [48], VCAM1 [49]) which mediate the

Table 7 pMSCs modulate expression of genes mediating endothelial cell (EC) permeability and leukocyte infiltration of ECs

\begin{tabular}{|c|c|c|c|c|c|c|}
\hline Number & Gene symbol & Gene full name & $\begin{array}{l}\text { Glucose } \\
\Delta \Delta^{-2} \text { value }\end{array}$ & $\begin{array}{l}\text { Glucose + ICpMSC } \\
\Delta \Delta^{-2} \text { value }\end{array}$ & $\begin{array}{l}\text { Fold change, glucose } \\
\text { compared with glucose }+ \\
\text { ICpMSC }(p<0.05)\end{array}$ & Biological activity \\
\hline 1 & ALOX5 & Arachidonate 5-lipoxygenase & 103.45 & 0.82 & 126.15-fold $\downarrow$ & \multirow[t]{5}{*}{ Induces EC permeability } \\
\hline 2 & $N P P B$ & Natriuretic peptide B & 4.12 & 0.04 & 103-fold $\downarrow$ & \\
\hline 3 & $\mathbb{L} 1 \beta$ & Interleukin 1 beta & 3.37 & 23.52 & 6.97-fold $\uparrow$ & \\
\hline 4 & IL6 & Interleukin 6 & 0.43 & 32.23 & 74.95 -fold $\uparrow$ & \\
\hline 5 & ICAMI & Intercellular adhesion molecule 1 & 11.5 & 642.79 & 55.89 -fold $\uparrow$ & \\
\hline 6 & CAV1 & Caveolin-1 & 5.87 & 2.5 & 2.34-fold $\downarrow$ & \multirow{2}{*}{$\begin{array}{l}\text { Inhibits EC } \\
\text { permeability }\end{array}$} \\
\hline 7 & NPR1 & Atrionatriuretic peptide receptor A & 1.16 & 12.58 & 10.84-fold $\uparrow$ & \\
\hline 1 & ENG & Endoglin & 60.47 & 1.89 & 31.99-fold $\downarrow$ & \multirow{4}{*}{$\begin{array}{l}\text { Induces leukocyte } \\
\text { infiltration }\end{array}$} \\
\hline 2 & VCAM1 & Vascular cell adhesion molecule 1 & 64.03 & 1.19 & 53.8 -fold $\downarrow$ & \\
\hline 3 & SELL & Selectin L & 22.05 & 359.67 & 16.3-fold $\uparrow$ & \\
\hline 4 & SELE & E-selectin & 22.05 & 359.67 & 16.31-fold $\uparrow$ & \\
\hline
\end{tabular}




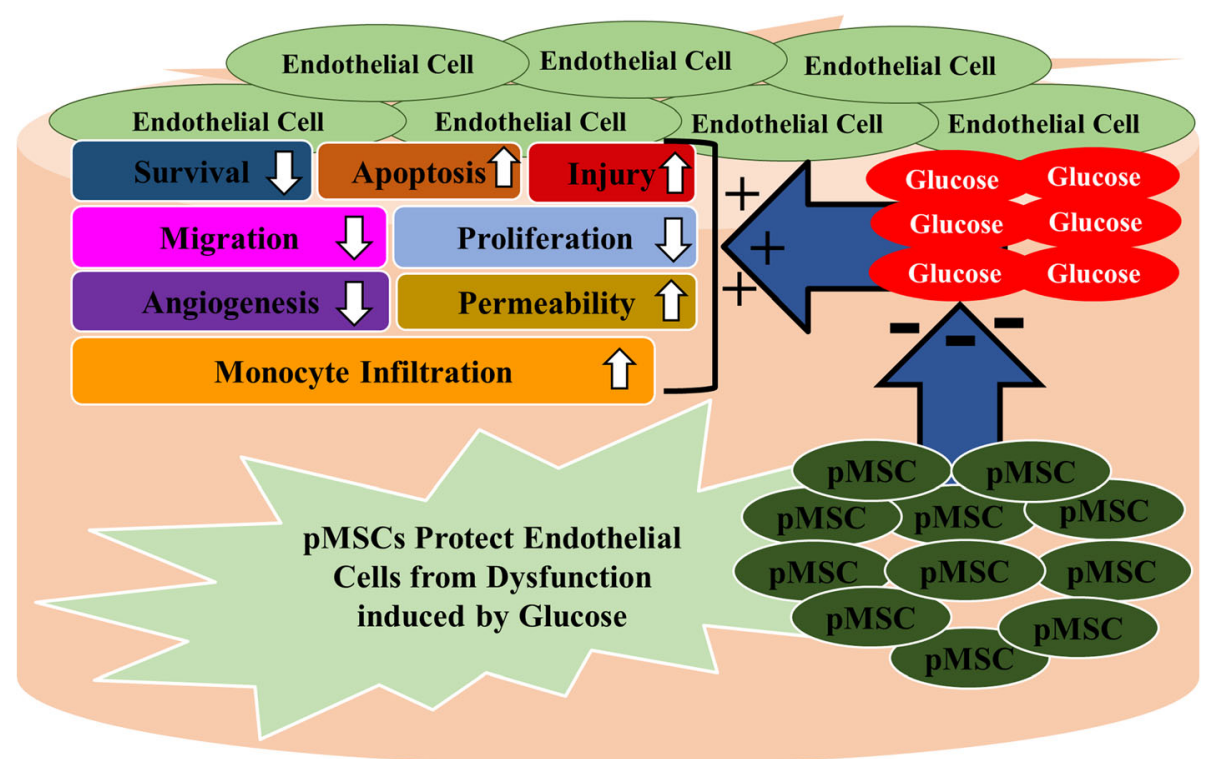

Fig. 9 Proposed effects of placental mesenchymal stem cells (pMSCs) on modifying negative impact of glucose on endothelial cell functions. pMSCs prevent endothelial cell injury and apoptosis from glucose and reverse inhibitory effects of glucose on endothelial cell survival, proliferation, migration, and angiogenesis. PMSCs also reduce stimulatory effects of glucose on endothelial cell permeability and monocyte infiltration through endothelial cells

infiltration of monocytes into endothelium (Tables 4 and 7). As for angiogenesis, pMSCs (CMpMSC and ICpMSC) showed a dual effect on endothelial expression of pro-invasion (ICAM1, IL1 $\beta$, and IL6), anti-invasion (CAV1), and pro-infiltration (SELL and SELE) genes (Tables 4 and 7). Together, these data provide evidence of multiple protective roles that pMSCs have on the permeability of endothelial cells via mechanisms that involve the genes indicated. This protective role of pMSCs was further supported by the ability of pMSCs to induce glucose-treated endothelial cell expression of various genes mediating their survival (i.e. EDN1 [50, 51], TYMP [52], PROCR [53], F2R [35, 53], TGFB1 [54], BCL2L1 [55], MMP1 [56], KDR [57], SPHK1 [58], TNFSF10 [59]) (Tables 2 and 5). Finally, pMSCs reduced glucose-treated endothelial cell expression of genes that induce their apoptosis (FASLG [60]), injury (ENG [48], CX3CL1 [61], F3 [62], THBD [62], AGTR1 [63]), and inflammation (IL3 [64], ALOX5 [65], FLT1 [66]) (Tables 2 and 5). These data further support pMSCs having a beneficial effect on multiple endothelial cell functions in the presence of glucose.

\section{Conclusions}

This is the first comprehensive study to provide evidence for a protective role of pMSCs on endothelial cells in an oxidative stress environment induced by glucose. pMSCs protect important functions of endothelial cells (i.e. proliferation, migration, angiogenesis, and permeability) from the negative impact of glucose (Fig. 9). Endothelial cell injury is a hallmark of vascular diseases, such as diabetes, that results in adverse complications leading to thrombosis and atherosclerosis. Therefore, we propose that pMSCs are promising candidates for stem cellbased therapies to treat vascular injury and the adverse complications associated with inflammatory diseases, such as diabetes and cardiovascular diseases. However, the therapeutic value of pMSCs needs to be determined in future animal studies.

\section{Acknowledgements}

The authors appreciate the staff and patients of the Delivery Unit, King Abdul Aziz Medical City for giving the placentae.

Funding

This study was supported by grants from KAIMRC (Grant No. RC12/133).

\section{Availability of data and materials}

All data generated during this study are included in this published article.

\section{Authors' contributions}

MHA proposed and supervised the project, and designed the experiments. YSB, AMAS, and EB performed the experiments. MHA, YSB, and TK analysed the data. MHA wrote the manuscript. MHA, YSB, TK, FMA, BK, MA-A, MAA, and ASA contributed to data analysis and interpretation of results. All authors reviewed the manuscript. All authors read and approved the final manuscript.

\section{Ethics approval and consent to participate}

The institutional review board (IRB) at King Abdulla International Medical Research Centre (KAIMRC), Saudi Arabia approved this study. Samples (i.e. placentae and umbilical cords) were obtained from uncomplicated human pregnancies (38-40 gestational weeks) following informed patient consent.

Consent for publication

Not applicable. All authors agree to publish this manuscript. 


\section{Competing interests}

The authors declare that they have no competing interests.

\section{Publisher's Note}

Springer Nature remains neutral with regard to jurisdictional claims in published maps and institutional affiliations.

\section{Author details}

'Stem Cells and Regenerative Medicine Department, King Abdullah International Medical Research Centre, King Abdulaziz Medical City, Ministry of National Guard Health Affairs, P.O. Box 22490, Mail Code 1515, Riyadh 11426, Saudi Arabia. ${ }^{2}$ National Center for Stem Cell Technology, Life Sciences and Environment Research Institute, King Abdulaziz City for Science and Technology, P.O. Box 6086, Riyadh 11442, Saudi Arabia. ${ }^{3}$ Stem Cell and Tissue Re-Engineering Program, King Faisal Specialist Hospital and Research Centre, Collage of Medicine, Al-Faisal University, MBC-03, P.O. Box 3354, Riyadh 11211, Saudi Arabia. ${ }^{4}$ Division of Obstetrics and Gynecology, Department of Clinical Science, Intervention and Technology, Karolinska Institutet, 14186 Stockholm, Sweden. ${ }^{5}$ Center for Hematology and Regenerative Medicine, Karolinska Institutet, 14186 Stockholm, Sweden. ${ }^{6}$ Department of MaternalFetal Medicine Pregnancy Research Centre and University of Melbourne Department of Obstetrics and Gynaecology, Royal Women's Hospital, Parkville, VIC 3052, Australia. ${ }^{7}$ College of Medicine, King Saud Bin Abdulaziz University for Health Sciences, King Abdulaziz Medical City, Ministry of National Guard Health Affairs, P.O. Box 3660, Mail Code 3124, Riyadh 11481, Saudi Arabia. ${ }^{8}$ Adult Hematology and Stem Cell Transplantation, King Abdulaziz Medical City, Ministry of National Guard Health Affairs, P.O. Box 22490, Mail Code 1515, Riyadh 11426, Saudi Arabia. ${ }^{9}$ College of Science and Health Professions, King Saud Bin Abdulaziz University for Health Sciences, King Abdulaziz Medical City, Ministry of National Guard Health Affairs, P.O. Box 3660, Mail Code 3124, Riyadh 11481, Saudi Arabia.

Received: 25 May 2018 Revised: 31 July 2018

Accepted: 15 August 2018 Published online: 21 September 2018

\section{References}

1. Prentki M, Nolan CJ. Islet beta cell failure in type 2 diabetes. J Clin Invest. 2006;116(7):1802-12. https://doi.org/10.1172/JCI29103. PubMed PMID: 16823478; PubMed Central PMCID: PMCPMC1483155

2. Beckman JA, Creager MA, Libby P. Diabetes and atherosclerosis: epidemiology, pathophysiology, and management. JAMA. 2002;287(19): 2570-81. PubMed PMID: 12020339

3. Morel O, Kessler L, Ohlmann P, Bareiss P. Diabetes and the platelet: toward new therapeutic paradigms for diabetic atherothrombosis. Atherosclerosis. 2010;212(2):367-76. https://doi.org/10.1016/j.atherosclerosis.2010.03.019. PubMed PMID: 20394927

4. Ferreiro $\mathrm{J}$, Angiolillo DJ. Diabetes and antiplatelet therapy in acute coronary syndrome. Circulation. 2011;123(7):798-813. https://doi.org/10. 1161/CIRCULATIONAHA.109.913376. PubMed PMID: 21343595

5. Paneni F, Beckman JA, Creager MA, Cosentino F. Diabetes and vascular disease: pathophysiology, clinical consequences, and medical therapy: part I. Eur Heart J. 2013;34(31):2436-43. https://doi.org/10.1093/eurheartj/eht149. PubMed PMID: 23641007; PubMed Central PMCID: PMCPMC3743069

6. Giacco F, Brownlee M. Oxidative stress and diabetic complications. Circ Res. 2010;107(9):1058-70. https://doi.org/10.1161/CIRCRESAHA.110.223545. PubMed PMID: 21030723; PubMed Central PMCID: PMCPMC2996922

7. Tabit CE, Chung WB, Hamburg NM, Vita JA. Endothelial dysfunction in diabetes mellitus: molecular mechanisms and clinical implications. Rev Endocr Metab Disord. 2010;11(1):61-74. https://doi.org/10.1007/s11154-0109134-4. PubMed PMID: 20186491; PubMed Central PMCID: PMCPMC2882637

8. Carr ME. Diabetes mellitus: a hypercoagulable state. J Diabetes Complicat 2001;15(1):44-54. PubMed PMID: 11259926

9. Emerging Risk Factors C, Di Angelantonio E, Kaptoge S, Wormser D, Willeit $P$, Butterworth AS, et al. Association of cardiometabolic multimorbidity with mortality. JAMA. 2015;314(1):52-60. https://doi.org/10.1001/jama.2015.7008. PubMed PMID: 26151266; PubMed Central PMCID: PMCPMC4664176

10. Booth GL, Kapral MK, Fung K, Tu JV. Relation between age and cardiovascular disease in men and women with diabetes compared with non-diabetic people: a population-based retrospective cohort study. Lancet. 2006;368(9529):29-36. https://doi.org/10.1016/S0140-6736(06)68967-8. PubMed PMID: 16815377
11. Abumaree $\mathrm{MH}, \mathrm{Al}$ Jumah MA, Kalionis B, Jawdat D, Al Khaldi A, AlTalabani $A A$, et al. Phenotypic and functional characterization of mesenchymal stem cells from chorionic villi of human term placenta. Stem Cell Rev. 2013;9(1): 16-31. https://doi.org/10.1007/s12015-012-9385-4. PubMed PMID: 22628114

12. Abumaree $M H$, Al Jumah MA, Kalionis B, Jawdat D, Al Khaldi A, Abomaray FM, et al. Human placental mesenchymal stem cells (pMSCs) play a role as immune suppressive cells by shifting macrophage differentiation from inflammatory M1 to anti-inflammatory M2 macrophages. Stem Cell Rev. 2013:9(5):620-41. https://doi.org/10.1007/s12015-013-9455-2. PubMed PMID: 23812784

13. Abomaray FM, Al Jumah MA, Kalionis B, AlAskar AS, Al Harthy S, Jawdat D, et al. Human chorionic villous mesenchymal stem cells modify the functions of human dendritic cells, and induce an anti-inflammatory phenotype in CD1+ dendritic cells. Stem Cell Rev. 2015;11(3):423-41. https://doi.org/10.1007/s12015-014-9562-8. PubMed PMID: 25287760

14. Abumaree MH, Hakami M, Abomaray FM, Alshabibi MA, Kalionis B, Al Jumah MA, et al. Human chorionic villous mesenchymal stem/stromal cells modify the effects of oxidative stress on endothelial cell functions. Placenta. 2017; 59:74-86. https://doi.org/10.1016/j.placenta.2017.05.001. PubMed PMID: 28502524

15. Alshabibi MA, Al Huqail AJ, Khatlani T, Abomaray FM, Alaskar AS, Alawad $A O$, et al. Mesenchymal stem/multipotent stromal cells from human decidua basalis reduce endothelial cell activation. Stem Cells Dev. 2017; 26(18):1355-73. https://doi.org/10.1089/scd.2017.0096. PubMed PMID: 28679316

16. Abomaray FM, Al Jumah MA, Alsaad KO, Jawdat D, Al Khaldi A, AlAskar AS, et al. Phenotypic and functional characterization of mesenchymal stem/ multipotent stromal cells from decidua basalis of human term placenta. Stem Cells Int. 2016;2016:5184601. https://doi.org/10.1155/2016/5184601. PubMed PMID: 27087815: PubMed Central PMCID: PMCPMC4764756

17. Braekke K, Harsem NK, Staff AC. Oxidative stress and antioxidant status in fetal circulation in preeclampsia. Pediatr Res. 2006;60(5):560-4. https://doi. org/10.1203/01.pdr.0000242299.01219.6a. PubMed PMID: 16988193

18. Kusuma GD, Abumaree MH, Pertile MD, Perkins AV, Brennecke SP, Kalionis B. Mesenchymal stem/stromal cells derived from a reproductive tissue niche under oxidative stress have high aldehyde dehydrogenase activity. Stem Cell Rev. 2016;12(3):285-97. https://doi.org/10.1007/s12015-016-9649-5. PubMed PMID: 26880140

19. Stout RW. Glucose inhibits replication of cultured human endothelial cells. Diabetologia. 1982;23(5):436-9. PubMed PMID: 7173520

20. Moriya J, Ferrara N. Inhibition of protein kinase $C$ enhances angiogenesis induced by platelet-derived growth factor $C$ in hyperglycemic endothelial cells. Cardiovasc Diabetol. 2015;14:19. https://doi.org/10.1186/s12933-0150180-9. PubMed PMID: 25849290; PubMed Central PMCID: PMCPMC4334399

21. Fang K, Fu W, Beardsley AR, Sun X, Lisanti MP, Liu J. Overexpression of caveolin-1 inhibits endothelial cell proliferation by arresting the cell cycle at G0/G1 phase. Cell Cycle. 2007;6(2):199-204. https://doi.org/10.4161/cc.6.2. 3740. PubMed PMID: 17245131

22. Clement B, Musso O, Lietard J, Theret N. Homeostatic control of angiogenesis: a newly identified function of the liver? Hepatology. 1999;29(3):621-3. https://doi.org/10.1002/hep.510290341. PubMed PMID: 10051458

23. Radisavljevic Z, Avraham H, Avraham S. Vascular endothelial growth factor up-regulates ICAM-1 expression via the phosphatidylinositol $3 \mathrm{OH}$-kinase/ AKT/nitric oxide pathway and modulates migration of brain microvascular endothelial cells. J Biol Chem. 2000;275(27):20770-4. https://doi.org/10.1074/ jbc.M002448200. PubMed PMID: 10787417

24. Hamuro M, Polan J, Natarajan M, Mohan S. High glucose induced nuclear factor kappa B mediated inhibition of endothelial cell migration. Atherosclerosis. 2002;162(2):277-87. PubMed PMID: 11996947

25. Daher Z, Noel J, Claing A. Endothelin-1 promotes migration of endothelial cells through the activation of ARF6 and the regulation of FAK activity. Cell Signal. 2008;20(12):2256-65. https://doi.org/10.1016/j.cellsig.2008.08.021. PubMed PMID: 18814847

26. Sarabi A, Kramp BK, Drechsler M, Hackeng TM, Soehnlein O, Weber C, et al. CXCL4L1 inhibits angiogenesis and induces undirected endothelial cell migration without affecting endothelial cell proliferation and monocyte recruitment. J Thromb Haemost. 2011;9(1):209-19. https://doi.org/10.1111/j. 1538-7836.2010.04119.x. PubMed PMID: 20961394

27. Paik JH, Chae S, Lee MJ, Thangada S, Hla T. Sphingosine 1-phosphateinduced endothelial cell migration requires the expression of EDG-1 and EDG-3 receptors and rho-dependent activation of alpha vbeta3- and beta1- 
containing integrins. J Biol Chem. 2001;276(15):11830-7. https://doi.org/10 1074/jbc.M009422200. PubMed PMID: 11150298

28. Yao JS, Zhai W, Young WL, Yang GY. Interleukin-6 triggers human cerebral endothelial cells proliferation and migration: the role for KDR and MMP-9. Biochem Biophys Res Commun. 2006;342(4):1396-404. https://doi.org/10. 1016/j.bbrc.2006.02.100. PubMed PMID: 16516857

29. Li A, Dubey S, Varney ML, Dave BJ, Singh RK. IL-8 directly enhanced endothelial cell survival, proliferation, and matrix metalloproteinases production and regulated angiogenesis. J Immunol. 2003;170(6):3369-76. PubMed PMID: 12626597

30. Lai Y, Shen Y, Liu XH, Zhang Y, Zeng Y, Liu YF. Interleukin-8 induces the endothelial cell migration through the activation of phosphoinositide 3 kinase-Rac1/RhoA pathway. Int J Biol Sci. 2011;7(6):782-91. PubMed PMID: 21750647; PubMed Central PMCID: PMCPMC3133886

31. Verma SK, Garikipati VN, Krishnamurthy P, Khan M, Thorne T, Qin G, et al. IL10 accelerates re-endothelialization and inhibits post-injury intimal hyperplasia following carotid artery denudation. PLoS One. 2016;11(1): e0147615. https://doi.org/10.1371/journal.pone.0147615. PubMed PMID: 26808574: PubMed Central PMCID: PMCPMC4725953

32. Kirkiles-Smith NC, Mahboubi K, Plescia J, McNiff JM, Karras J, Schechner JS, et al. IL-11 protects human microvascular endothelium from alloinjury in vivo by induction of survivin expression. J Immunol. 2004;172(3):1391-6. PubMed PMID: 14734714

33. Heldin $\mathrm{CH}$, Ostman A, Ronnstrand L. Signal transduction via platelet-derived growth factor receptors. Biochim Biophys Acta. 1998;1378(1):F79-113. PubMed PMID: 9739761

34. Celerier J, Cruz A, Lamande N, Gasc JM, Corvol P. Angiotensinogen and its cleaved derivatives inhibit angiogenesis. Hypertension. 2002;39(2):224-8. PubMed PMID: 11847188

35. Zania P, Kritikou S, Flordellis CS, Maragoudakis ME, Tsopanoglou NE. Blockade of angiogenesis by small molecule antagonists to proteaseactivated receptor-1: association with endothelial cell growth suppression and induction of apoptosis. J Pharmacol Exp Ther. 2006;318(1):246-54. https://doi.org/10.1124/jpet.105.099069. PubMed PMID: 16595737

36. Ribatti $\mathrm{D}$. The discovery of the placental growth factor and its role in angiogenesis: a historical review. Angiogenesis. 2008;11(3):215-21. https:// doi.org/10.1007/s10456-008-9114-4. PubMed PMID: 18568405

37. Niu J, Wang K, Zhelyabovska O, Saad Y, Kolattukudy PE. MCP-1-induced protein promotes endothelial-like and angiogenic properties in human bone marrow monocytic cells. J Pharmacol Exp Ther. 2013;347(2):288-97. https://doi.org/10.1124/jpet.113.207316. PubMed PMID: 24008336; PubMed Central PMCID: PMCPMC3807059

38. Reed MJ, Koike T, Sadoun E, Sage EH, Puolakkainen P. Inhibition of TIMP1 enhances angiogenesis in vivo and cell migration in vitro. Microvasc Res. 2003:65(1):9-17. PubMed PMID: 12535866

39. Lopez-Pastrana J, Ferrer LM, Li YF, Xiong $X, X i H$, Cueto R, et al. Inhibition of Caspase-1 activation in endothelial cells improves angiogenesis: a novel therapeutic potential for ischemia. J Biol Chem. 2015;290(28):17485-94. https://doi.org/10.1074/jbc.M115.641191. PubMed PMID: 26037927; PubMed Central PMCID: PMCPMC4498083

40. He T, Lu T, d'Uscio LV, Lam CF, Lee HC, Katusic ZS. Angiogenic function of prostacyclin biosynthesis in human endothelial progenitor cells. Circ Res. 2008;103(1):80-8. https://doi.org/10.1161/CIRCRESAHA.108.176057. PubMed PMID: 18511850; PubMed Central PMCID: PMCPMC2664088

41. Li W, Ren G, Huang Y, Su J, Han Y, Li J, et al. Mesenchymal stem cells: a double-edged sword in regulating immune responses. Cell Death Differ. 2012;19(9):1505-13. https://doi.org/10.1038/cdd.2012.26. PubMed PMID: 22421969; PubMed Central PMCID: PMCPMC3422473

42. Sgadari C, Angiolillo AL, Tosato G. Inhibition of angiogenesis by interleukin12 is mediated by the interferon-inducible protein 10. Blood. 1996;87(9): 3877-82. PubMed PMID: 8611715

43. Dace DS, Khan AA, Kelly J, Apte RS. Interleukin-10 promotes pathological angiogenesis by regulating macrophage response to hypoxia during development. PLoS One. 2008;3(10):e3381. https://doi.org/10.1371/journal. pone.0003381. PubMed PMID: 18852882; PubMed Central PMCID: PMCPMC2557127

44. Zhao XY, Wang XF, Li L, Zhang L, Shen DL, Li DH, et al. Effects of high glucose on human umbilical vein endothelial cell permeability and myosin light chain phosphorylation. Diabetol Metab Syndr. 2015;7:98. https://doi. org/10.1186/s13098-015-0098-0. PubMed PMID: 26583048; PubMed Central PMCID: PMCPMC4650340
45. Valdivielso JM, Montero A, Badr KF, Munger KA. Inhibition of 5-lipoxygenase activating protein decreases proteinuria in diabetic rats. J Nephrol. 2003; 16(1):85-94. PubMed PMID: 12649539

46. Chen W, Gassner B, Borner S, Nikolaev VO, Schlegel N, Waschke J, et al. Atrial natriuretic peptide enhances microvascular albumin permeability by the caveolae-mediated transcellular pathway. Cardiovasc Res. 2012;93(1): 141-51. https://doi.org/10.1093/cvr/cvr279. PubMed PMID: 22025581; PubMed Central PMCID: PMCPMC3243041

47. Furst R, Bubik MF, Bihari P, Mayer BA, Khandoga AG, Hoffmann F, et al. Atrial natriuretic peptide protects against histamine-induced endothelial barrier dysfunction in vivo. Mol Pharmacol. 2008;74(1):1-8. https://doi.org/10.1124/ mol.108.045773. PubMed PMID: 18413663

48. Rossi E, Sanz-Rodriguez F, Eleno N, Duwell A, Blanco FJ, Langa C, et al. Endothelial endoglin is involved in inflammation: role in leukocyte adhesion and transmigration. Blood. 2013;121(2):403-15. https://doi.org/10.1182/ blood-2012-06-435347. PubMed PMID: 23074273

49. Esposito C, Fasoli G, Plati AR, Bellotti N, Conte MM, Cornacchia F, et al. Longterm exposure to high glucose up-regulates VCAM-induced endothelial cell adhesiveness to PBMC. Kidney Int. 2001;59(5):1842-9. https://doi.org/10.1046/j. 1523-1755.2001.0590051842.x. PubMed PMID: 11318955

50. Dong F, Zhang X, Wold LE, Ren Q, Zhang Z, Ren J. Endothelin-1 enhances oxidative stress, cell proliferation and reduces apoptosis in human umbilical vein endothelial cells: role of ETB receptor, NADPH oxidase and caveolin-1. Br. Aust J Pharm. 2005;145(3):323-33. https://doi.org/10.1038/sj.bjp.0706193. PubMed PMID: 15765100; PubMed Central PMCID: PMCPMC1576147

51. Mikhail M, Vachon PH, D'Orleans-Juste P, Jacques D, Bkaily G. Role of endothelin-1 and its receptors, ETA and ETB, in the survival of human vascular endothelial cells. Can J Physiol Pharmacol. 2017;95(10):1298-305. https://doi.org/10.1139/cjpp-2017-0412. PubMed PMID: 28732172

52. Sengupta S, Sellers LA, Matheson HB, Fan TP. Thymidine phosphorylase induces angiogenesis in vivo and in vitro: an evaluation of possible mechanisms. Br J Pharmacol. 2003;139(2):219-31. https://doi.org/10.1038/s. bjp.0705216. PubMed PMID: 12770927; PubMed Central PMCID: PMCPMC1573835

53. Bock F, Shahzad K, Wang H, Stoyanov S, Wolter J, Dong W, et al. Activated protein $C$ ameliorates diabetic nephropathy by epigenetically inhibiting the redox enzyme p66Shc. Proc Natl Acad Sci U S A. 2013;110(2):648-53. https://doi.org/10.1073/pnas.1218667110. PubMed PMID: 23267072; PubMed Central PMCID: PMCPMC3545757

54. Vinals F, Pouyssegur J. Transforming growth factor beta1 (TGF-beta1) promotes endothelial cell survival during in vitro angiogenesis via an autocrine mechanism implicating TGF-alpha signaling. Mol Cell Biol. 2001; 21(21):7218-30. https://doi.org/10.1128/MCB.21.21.7218-7230.2001. PubMed PMID: 11585905; PubMed Central PMCID: PMCPMC99897

55. Kern TS, Du Y, Miller CM, Hatala DA, Levin LA. Overexpression of BCl-2 in vascular endothelium inhibits the microvascular lesions of diabetic retinopathy. Am J Pathol. 2010;176(5):2550-8. https://doi.org/10.2353/ajpath. 2010.091062. PubMed PMID: 20363911; PubMed Central PMCID: PMCPMC2861119

56. Mazor R, Alsaigh T, Shaked H, Altshuler AE, Pocock ES, Kistler EB, et al. Matrix metalloproteinase-1-mediated up-regulation of vascular endothelial growth factor-2 in endothelial cells. J Biol Chem. 2013;288(1):598-607. https://doi. org/10.1074/jbc.M112.417451. PubMed PMID: 23155052; PubMed Central PMCID: PMCPMC3537058

57. Wang JF, Zhang $X$, Groopman JE. Activation of vascular endothelial growth factor receptor-3 and its downstream signaling promote cell survival under oxidative stress. J Biol Chem. 2004;279(26):27088-97. https://doi.org/10.1074/ jbc.M314015200. PubMed PMID: 15102829

58. Kwon YG, Min JK, Kim KM, Lee DJ, Billiar TR, Kim YM. Sphingosine 1phosphate protects human umbilical vein endothelial cells from serumdeprived apoptosis by nitric oxide production. J Biol Chem. 2001;276(14): 10627-33. https://doi.org/10.1074/jbc.M011449200. PubMed PMID: 11134047

59. Secchiero P, Gonelli A, Carnevale E, Milani D, Pandolfi A, Zella D, et al. TRAll promotes the survival and proliferation of primary human vascular endothelial cells by activating the Akt and ERK pathways. Circulation. 2003; 107(17):2250-6. https://doi.org/10.1161/01.CIR.0000062702.60708.C4. PubMed PMID: 12668516

60. Joussen AM, Poulaki V, Mitsiades N, Cai WY, Suzuma I, Pak J, et al. Suppression of Fas-FasL-induced endothelial cell apoptosis prevents diabetic blood-retinal barrier breakdown in a model of streptozotocin- 
induced diabetes. FASEB J. 2003;17(1):76-8. https://doi.org/10.1096/fj.020157fje. PubMed PMID: 12475915

61. Li G, Xu Y, Sheng X, Liu H, Guo J, Wang J, et al. Naringin protects against high glucose-induced human endothelial cell injury via antioxidation and CX3CL1 downregulation. Cell Physiol Biochem. 2017;42(6):2540-51. https:// doi.org/10.1159/000480215. PubMed PMID: 28848146

62. Stehouwer CD. Endothelial dysfunction in diabetic nephropathy: state of the art and potential significance for non-diabetic renal disease. Nephrol Dial Transplant. 2004;19(4):778-81. https://doi.org/10.1093/ndt/gfh015. PubMed PMID: 15031329

63. Willemsen JM, Westerink JW, Dallinga-Thie GM, van Zonneveld AJ, Gaillard CA, Rabelink TJ, et al. Angiotensin II type 1 receptor blockade improves hyperglycemia-induced endothelial dysfunction and reduces proinflammatory cytokine release from leukocytes. J Cardiovasc Pharmacol. 2007;49(1):6-12. https://doi.org/10.1097/FJC.0b013e31802b31a7. PubMed PMID: 17261957

64. Brizzi MF, Garbarino G, Rossi PR, Pagliardi GL, Arduino C, Avanzi GC, et al. Interleukin 3 stimulates proliferation and triggers endothelial-leukocyte adhesion molecule 1 gene activation of human endothelial cells. J Clin Invest. 1993;91(6):2887-92. https://doi.org/10.1172/JCl1 16534. PubMed PMID: 7685775; PubMed Central PMCID: PMCPMC443359

65. Sasson S, Davarashvili A, Reich R. Role of lipoxygenase in the regulation of glucose transport in aortic vascular cells. Adv Exp Med Biol. 1999;469:377-83. PubMed PMID: 10667356

66. Yang KS, Lim JH, Kim TW, Kim MY, Kim Y, Chung S, et al. Vascular endothelial growth factor-receptor 1 inhibition aggravates diabetic nephropathy through eNOS signaling pathway in $\mathrm{db} / \mathrm{db}$ mice. PLoS One. 2014;9(4):e94540. https://doi.org/10.1371/journal.pone.0094540. PubMed PMID: 24759928; PubMed Central PMCID: PMCPMC3997361

Ready to submit your research? Choose BMC and benefit from:

- fast, convenient online submission

- thorough peer review by experienced researchers in your field

- rapid publication on acceptance

- support for research data, including large and complex data types

- gold Open Access which fosters wider collaboration and increased citations

- maximum visibility for your research: over $100 \mathrm{M}$ website views per year

At $\mathrm{BMC}$, research is always in progress.

Learn more biomedcentral.com/submissions 